\title{
Study and Computer-aided Design of Flux-cored Wire Rolling in Round Gauges
}

\section{Eduard P. Gribkov ( $\nabla$ gribkov.eduard@gmail.com )}

Donbass State Engineering Academy https://orcid.org/0000-0002-1565-6294

\section{Serhii O. Malyhin}

Donbass State Engineering Academy

\section{Svetlana S. Hurkovskaya}

Donbass State Engineering Academy

\section{Elena V. Berezshnaya}

Donbass State Engineering Academy

Dmytro V. Merezhko

Donbass State Engineering Academy

\section{Research Article}

Keywords: Powder Wire, Rolling, Mathematical Model, Deformation Zone, Computer-Aided Design, Technological Modes, Round Gauge

Posted Date: May 18th, 2021

DOl: https://doi.org/10.21203/rs.3.rs-433003/v1

License: (c) (i) This work is licensed under a Creative Commons Attribution 4.0 International License. Read Full License 


\title{
STUDY AND COMPUTER-AIDED DESIGN OF FLUX-CORED WIRE ROLLING IN ROUND GAUGES
}

\author{
Eduard P. Gribkov ${ }^{1 *}$, Serhii O. Malyhin ${ }^{1}$, Svetlana S. Hurkovskaya ${ }^{2}$, Elena V. Berezshnaya ${ }^{3}$, \\ Dmytro V. Merezhko ${ }^{1}$
}

1 Automated Metal Forming Process and Machinery Department, Donbass State Engineering Academy, Akademichna 72, Kramatorsk, 84313, Donetsk Region, Ukraine

${ }^{2}$ Computer and information technology Department, Donbass State Engineering Academy, Akademichna 72 , Kramatorsk, 84313, Donetsk Region, Ukraine

${ }^{3}$ Handling systems and transport machines department, Donbass State Engineering Academy, Akademichna 72, Kramatorsk, 84313, Donetsk Region, Ukraine

*Corresponding author’s Email: gribkov.eduard@gmail.com

\begin{abstract}
The mathematical model of the stress-strain state during flux-cored wire rolling in round gauges has been developed. Simulation was based on dividing the deformation zone into elementary volumes and simultaneous solution of the plasticity condition for porous materials and power static equilibrium equation inside the elementary volume. A distinctive feature of this model is taking into account the porous medium strain in the deformation zone. The experiments have confirmed the validity of the mathematical model for predicting the powder density and the energy-power characteristics of the process. Based on the developed mathematical model, the criteria and conditions for optimization were formulated, and the algorithm was developed for the automated design of technology for fluxcored wire rolling in round gauges. As an example of the obtained solutions implementation, the calculation of sintered copper flux-cored wire rolling technology was given.
\end{abstract}

Keywords: Powder Wire, Rolling, Mathematical Model, Deformation Zone, Computer-Aided Design, Technological Modes, Round Gauge

\section{Nomenclature}

$L_{p l}-$ seal zone content;

$L_{\text {lag }}$ - backward slip zone content;

$L_{a d v}$ - forward slip zone content;

$a b, c d$ - boundary sections of deformation zone;

$p_{x}$ - standard surface stresses;

$d_{x}$-composition thickness along the deformation zone length;

$K_{R}$ - number of elementary volumes when the deformation zone is broken along the rolling axis;

$f_{x}$ - coefficient of external friction;

$L_{0}$ - billet length before rolling;

$L_{l}$ - billet length after rolling;

$S_{l 1}$ - relative length of the forward slip zone on the driving work roll;

\section{Greek}

$\sigma_{x}-$ standard axial stresses;

$\alpha_{x}-$ contact angle;

$\tau_{\mathrm{x}}-$ shear contact stresses;

$\varepsilon_{d x}, \varepsilon_{l x}$ - deformation degree;

$\gamma_{x}$ - density ratio;

$\sigma_{s x i}$ - solid phase yield strength;

$\varepsilon_{\text {ex }}$ - equivalent strain;

$\Delta \varepsilon_{\text {exj }}$ - equivalent strain increment;

$\sigma_{l}-$ front tension stress;

\section{Index}

$i$ - serial number of axial rolling section;

$x$ - coordinate along the rolling axis.

\section{State of the art and literature review}

One of the most widely used materials in the welding industry is flux-cored wire. Essentially, flux-cored wire is a metal sheath, filled with a powder core. It serves as a flux [1-3]. This type of wire is used as an auxiliary material in surfacing or in the welding process [4-8]. The production of flux-cored wire is carried out according to the following technological scheme. First of all, a U-shape is given to the metal tape of the sheath; then the profile is filled with a powder core; the filled form is wiredrawn several times; at the end, the finished product is coiled [6-10]. 
However, there is a flux-cored wire that is made sheathless [11-14]. This paper considers the production process for only sheathless flux-cored wire. It is used for welding non-ferrous metal parts such as copper or copper alloys. A distinctive feature of the technological process for the manufacture of such a wire is the process of preliminary powder extrusion [15]. Then, drawing in rolls is performed with round gauges of a specified diameter.

Many theories of porous materials plasticity are used for theoretical studies of the powder materials deformation. Simulation of the powder rolling process is not complete without the use of such phenomenological models of soil mechanics as the corrected C - M model, the Drucker - Prager - Cap model, and the Cam - Clay model [16-20].

Theoretical studies of the powder materials stress-strain state have been carried out by many scientists from all over the world. Thus, the authors of the paper [21] considered the process of rolling flux-cored wire, taking into account the backward slip and forward slip zones, that the distribution of stresses along the length of the deformation zone depends on. The plasticity conditions for powder materials were determined in the paper [22]. The use of joint finite-difference solutions of static equilibrium equations and plasticity conditions from the papers [23-27] allowed to develop mathematical models of the stress-strain state during powder rolling. The paper [28] is devoted to the study of the asymmetry influence on the process, while the authors of the paper [29-32] were engaged in determining the efficiency of the deformation-zone geometry monometallic component. Subsequently, this method was confirmed experimentally and became widespread for solving such problems [33-35, 36]. But a common feature of all these papers is the study of the flux-cored tape deformation in flat rolls, and the issue of rolling in grooved rolls was not discussed.

In order to study the stress-strain state of powder materials in the process of pressure treatment, finite element methods are used. The authors of the paper [16] established the dependence of the stress distribution over the cross section on the part configuration. The authors of the paper [17] were engaged in determining the parameters of the cover surface fracture and the hardening law of the constitutive model. A description of the powder composition pressing process using CAP models is presented in the paper [18]. Kailas [37] determined the distribution of friction on contact surfaces. In the papers [38] and [39], the features of rolling powder materials based on the finite element method are taken into account. In the paper [39], a mathematical model of powder rolling was constructed on the basis of continuum mechanics. The ellipsoidal yield criterion and the elastoplastic relationship are analyzed depending on the mechanical properties of the powder compaction. Taking into account the conditions of geometric nonlinearity, such as large displacement and large deformation, based on the updated formulation of Lagrange, the defining dependence of the incremental shape was derived. The theoretical and technical foundations for 3D elastoplastic modeling by the finite element powder rolling method were provided. The unsolved problems in these articles include the difficulties of solving computer-aided design issues of specific implementation methods.

The investigated process is essentially similar to the processes of rolling wire rod and drawing in roller dies. The authors of papers [40-45] were engaged in this study. The difference between these processes and simple drawing is the presence of backward and forward slip zones in the deformation site. Another feature of the considered flux-cored wire rolling process calculation is taking into account the relationship between stresses, deformations, and density of the flux-cored material.

All this makes it relevant to further research the process of rolling flux-cored wire in round gauges of a rolling mill.

\section{Introduction}

\subsection{Actuality of research}

Despite the number of papers devoted to the flux-cored electrodes production, the problem of determining the stress-strain state during rolling flux-cored wire in round gauges has not been solved. Known solutions in the field of rolling wire rod and drawing in roller dies are devoted to the continuum deformation. Recently, the most common method for the powder materials forming processes is the finite element method, but its use hampers performing automated calculations due to a specific implementation method. All this generates a need for developing a mathematical model of the rolling flux-cored wire in round gauges, based on the joint solution of the plasticity conditions for porous bodies and the equilibrium equations of the elementary volume in the deformation zone.

\subsection{Aims and scopes}

The aim of this work is to study the effect of reducing on the final relative density of flux-cored wire when rolling it in round gauges and to determine rational reduction modes based on the creation of a computer-aided design system for this technology. To achieve this goal, the following tasks were set and solved: a mathematical model of the material stress-strain state was developed and experimental studies of the rolling flux-cored wire in round passes were carried out.

\subsection{Prime novelty statement}

The main contribution to this area is the study of the rolling flux-cored wire in round gauges. The proposed model expands the understanding of the process and evaluates the influence of the initial characteristics on the finished wire.

Theoretically, for the first time, a mathematical model for rolling flux-cored wire in round gauges has been developed. The model is based on the joint solution of the conditions for static equilibrium of the deformation zone isolated elementary volume of a flux-cored wire. The model takes into account the real distribution of mechanical properties and friction conditions along the length of the deformation zone. A distinctive feature of the model is taking into account the deformation of the powder material in the round gauges.

In the experimental technique, for the first time, experimental studies of rolling flux-cored wire in round gauges were carried out, which revealed the influence of the initial parameters on the formation of the process power characteristics and the final density of the wire. 
In industrial applications, the results are interesting for developers of equipment for the production of flux-cored electrodes and technologists in the development of technology for the flux-cored wire production by rolling methods. The developed model allows us to determine the maximum values of the force, rolling torque and rolling power. The model helps to solve the problems of computer-aided design for flux-cored wire rolling modes by choosing optimal initial parameters, such as powder density and initial wire diameter.

\section{Theoretical research}

\subsection{Mathematical model}

In accordance with the above-mentioned and similar to the methods of paper $[33 ; 34]$, the considered numerical one-dimensional mathematical model of the pressed flux-cored wire rolling process was based on the numerical recurrent solution of the finite-difference form of the static equilibrium condition of the deformation zone selected elementary volume. The design diagram of the integral deformation zone included the seal zone $L_{p l}$ (Fig. 1a). Speaking from the perspective of the kinematic relations, the seal zone $L_{p l}$ was subdivided into the backward slip zone $L_{l a g}$ and the forward slip zone $L_{a d v}$.

Directly left $A B$ and right $C D$ boundary sections of the deformation zone in the framework of the considered mathematical model were taken parallel to the plane passing through the axes of the working rolls. The seal zone sections, including neutral sections, which are the backward and forward zones sections on the corresponding working rolls, were taken as parallel to this plane.

Besides the above-mentioned, when developing a one-dimensional mathematical model, a number of assumptions were used, the main of them are the following:

- mechanical properties values, standard axial stresses $\sigma_{x}$, standard contact stresses $p_{x}$, and rolling kinematic parameters change only along the length of the deformation zone, while their value remains constant along the thickness of each separate section;

- current values of the contact angle $\alpha_{x}$ along the length of each individual selected elementary volume do not change, while the changes in the standard $p_{x}$ and tangential $\tau_{x}$ contact stresses are linear (Fig. 1b);

- tangential contact stresses in the deformation zone are subjected the Coulomb-Amonton friction law, $\tau_{x}=f_{x} P_{x}$, while the analytical descriptions of the external friction coefficients distributions for both the backward zone and forward zones can be represented by power dependences of the following form:

$$
\begin{aligned}
f_{x 1(2)} & =f_{l a g 1(2)}\left[\frac{x-L_{a d v 1(2)}}{L_{p l}-L_{a d v 1(2)}}\right]^{a_{f 1(2)}} & & \text { at } L_{a d v 1(2)}<x \leq L_{p l} ; \\
f_{x 1(2)} & =f_{a d v 1(2)}\left[\frac{L_{a d v 1(2)}-x}{L_{a d v 1(2)}}\right]^{a_{f 1(2)}} & & \text { at } 0<x \leq L_{a d v 1(2),}
\end{aligned}
$$

where $x$ is a geometric coordinate originating in the plane of the seal zone coupling with the elastic recovery zone (Fig. 1a); $f_{l o g}, f_{a d v}$ - reference values of the friction coefficients corresponding to the values of these coefficients in the section at the input $\left(x=L_{p l}\right)$ and in the section at the output $(x=0)$ - from the seal zone; $a_{f}$ - power value characterizing the diagram shape of the friction coefficients distribution along the length of the contact surfaces on the leading and driven working rolls, respectively, $a_{f}=0.2-0.5 ; L_{a d v}, L_{l o g}$ - respectively the length of the forward and backward zones, on the contact surfaces of the working rolls.

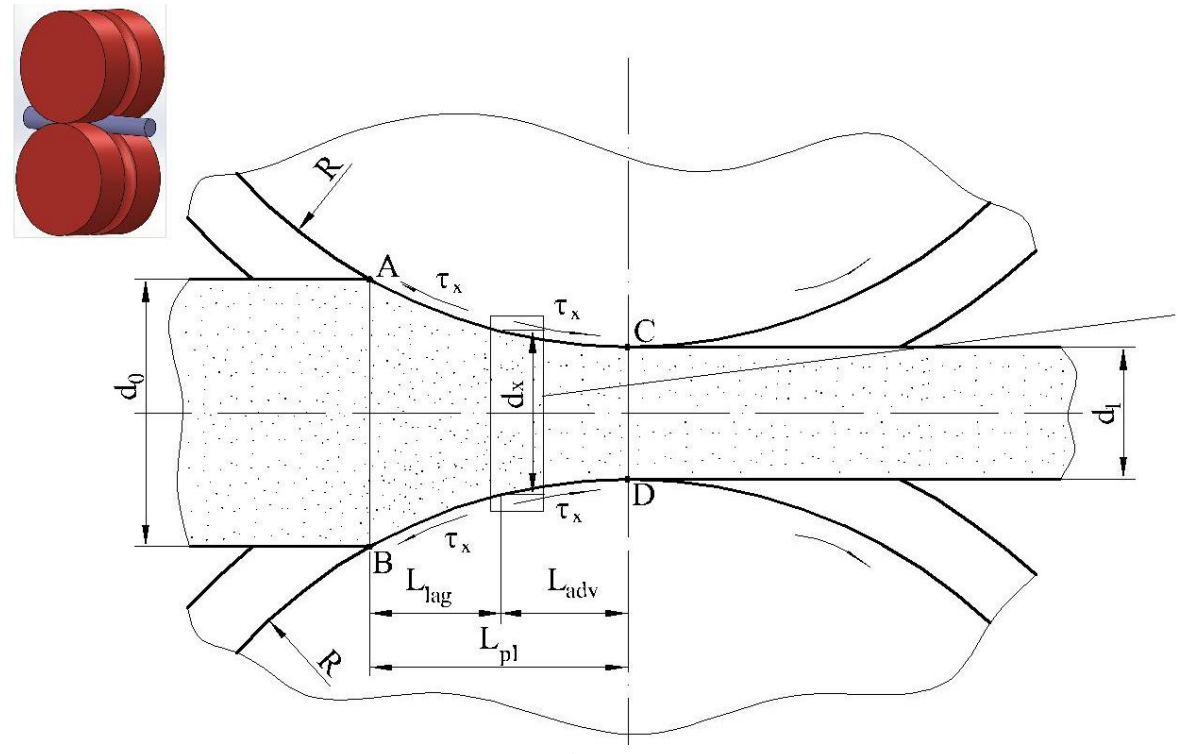

a)

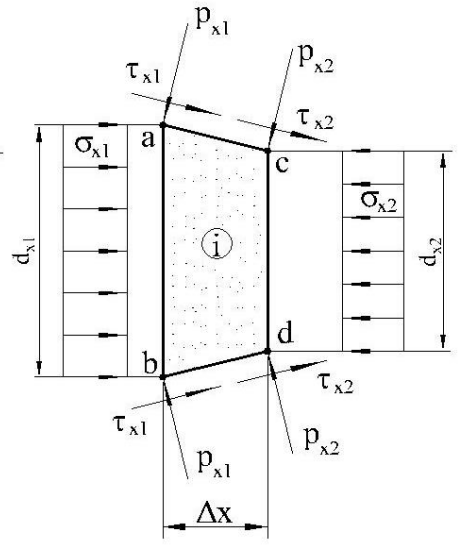

b)

Figure 1: Design diagram of the integral deformation zone (a) and the selected elementary volume (b) during the implementation of the pressed flux-cored wire rolling process 
As an analytical description of the composition thickness value current along the deformation zone length $d_{x}$, the power approximation of contact arcs was used:

$$
d_{x}=d_{1}+\left(d_{0}-d_{1}\right)\left(x / L_{p l}\right)^{a_{h}}
$$

where $d_{l}$ is the final thickness of the resulting wire (Fig. 1a); $a_{h}$ - power characteristic of the deformation zone shape, the quantitative assessment of which with the cylindrical working rolls can be taken equal to $a_{h}=2.0 ; d_{0}-$ is the initial thickness of the pressed flux-cored wire in the section at the input to the deformation zone (Fig. 1a).

Having carried out, taking into account the above-mentioned, the division of the deformation site seal zone into a finite aggregate $\left(K_{R}\right)$ of elementary volumes and expressions, based on the nature of the assumptions made, the geometric characteristics, and the stresses $\sigma_{x}, \tau_{x}$ and $p_{x}$ in finite-difference form, as shown in Fig. 1b, let's consider the condition of static equilibrium of the selected i-th elementary volume:

$$
\begin{gathered}
\sum F x=\sigma_{x_{1}} F_{x_{1}}-\sigma_{x_{2}} F_{x_{2}}-\int_{x_{1}}^{x_{2}} \pi\left[p_{x_{1}}+\left(p_{x_{2}}-p_{x_{1}}\right) \frac{x-x_{1}}{x_{2}-x_{1}}\right]\left[d x_{1}+\left(d x_{1}-d x_{2}\right) \frac{x-x_{1}}{x_{2}-x_{1}}\right] \times \\
\times \operatorname{tg} \alpha_{x} d x+\int_{x_{1}}^{x_{2}} \pi\left[\tau_{x_{1}}+\left(\tau_{x_{2}}-\tau_{x_{1}}\right) \frac{x-x_{1}}{x_{2}-x_{1}}\right]\left[d x_{1}+\left(d x_{1}-d x_{2}\right) \frac{x-x_{1}}{x_{2}-x_{1}}\right] d x=0,
\end{gathered}
$$

where positive values of standard stresses $\sigma_{x}$ correspond to compression stresses, and the opposite direction of tangential contact stresses in backward and forward slip zones (Fig. 1a) is taken into account by signs in the analytical description (1) - (2) of external friction coefficients $f_{x}$ distributions on working rolls; $\Delta x=l / K_{R}$ - the seal zone subinterval; $x_{1}, x_{2}=x_{1}-\Delta x$ - geometric coordinates of the initial and final section of each separate selected elementary volume; $d_{x l}, d_{x 2}$ - thickness of the rolled composition in the initial and final sections, determined according to (3) depending on the corresponding values of the geometric coordinates $x_{1}$ and $x_{2} ; \sigma_{x l}, p_{x l}, \sigma_{x 2}, p_{x 2}$ are normal and standard contact stresses that occur, respectively, for the initial and final sections of a given elementary volume.

The solution to the integrand of the form (4) is the expression: where:

$$
\pi \operatorname{tg} \alpha x\left[\int_{x 1}^{x 2} t_{6} x^{2} d x+\int_{x 1}^{x 2} t_{5} x d x+\int_{x 1}^{x 2} t_{4} d x\right]=\left(\frac{1}{3} t_{6} x_{2}^{3}+t_{4} x_{2}+\frac{1}{2} t_{5} x_{2}^{2}-\frac{1}{3} t_{6} x_{1}^{3}-t_{4} x_{1}-\frac{1}{2} t_{5} x_{1}^{2}\right) \pi d x
$$

$$
\begin{gathered}
t_{1}=p_{x_{1 i}} d x_{1 i} ; \\
t_{2}=p_{x_{1} i}\left(d x_{1 i}-d x_{2 i}\right) ; \\
t_{3}=\left(p_{x_{2 i}}-p_{x_{1} i}\right)\left(d x_{1 i}-d x_{2 i}\right) ; \\
t_{4}=p x_{1 i} d x_{1 i}-\frac{x_{1} p_{x_{1 i}}\left(d x_{1 i}-d x_{2 i}\right)}{x_{2}-x_{1}}+\frac{x_{1}}{\left(x_{2}-x_{1}\right)^{2}} ; \\
t_{5}=\frac{p_{x_{1 i}}\left(d x_{1 i}-d x_{2 i}\right)}{x_{2}-x_{1}}-\frac{2\left(p_{x_{2 i}}-p_{x_{1 i}}\right)\left(d x_{1 i}-d x_{2 i}\right)}{\left(x_{2}-x_{1}\right)^{2}} ; \\
t_{6}=\frac{\left(p_{x_{2 i}}-p_{x_{1 i}}\right)\left(d x_{1 i}-d x_{2 i}\right)}{\left(x_{2}-x_{1}\right)^{2}} .
\end{gathered}
$$

Besides the static equilibrium condition (4), normal $\sigma_{x}$ and normal contact $p_{x}$ stresses are functionally related to each other by the plasticity condition, its analytical description, taking into account the assumption of the powder medium axisymmetric stress-strain state, has the following form [22]:

$$
\sigma_{x}^{2}-2 \sigma_{x} p_{x} \frac{1-2 \alpha_{x}}{1+\alpha_{x}}+p_{x}^{2} \frac{1+4 \alpha_{x}}{1+\alpha_{x}}=\frac{1}{1+\alpha_{x}} \beta_{x} \sigma_{s x}^{2}
$$

where $\alpha_{x}, \beta_{x}$ - coefficients values current along the deformation zone length, taking into account the specifics of the powder medium deformation; $\sigma_{s x}$ is the current value of the yield strength for the solid phase of this powder composition.

The current values of the coefficients $\alpha_{x}$ and $\beta_{x}$, according to the recommendations of the paper [22], can be determined as:

$$
\alpha_{x}=a\left(1-\gamma_{x}\right)^{m} ; \beta_{x}=\gamma_{x}^{2 n}
$$

where $\gamma_{x}=\rho_{x} / \rho_{0}$ - is the rolled material relative density value current along the deformation zone length; $\rho_{x} / \rho_{0}-$ current density and the given powder composition solid phase density; $a, m, n$-invariables for each coefficient value specific content, characterizing the intensity of $\alpha_{x}$ and $\beta_{x}$ changes depending on the change in the relative density indicator $\gamma_{x}$.

For sintered copper powder at $\gamma=0.85 \ldots 0.98$, according to the recommendation of the paper [22], we take $a=0.633, m=1.017, n=1.94$.

Let us express from the equation (7) the value of normal stresses $\sigma_{x}$ :

$$
\sigma_{x}=p_{x} \frac{1-2 \alpha_{x}}{1+\alpha_{x}} \pm \sqrt{\frac{\beta_{x} \sigma_{s x}^{2}}{1+\alpha_{x}}-p_{x}^{2} \frac{9 \alpha_{x}}{\left(1+\alpha_{x}\right)^{2}}} .
$$

Substituting the Coulomb-Amonton friction law and the plasticity condition (9) into equation (5), we determine the normal contact stresses $p_{x 2}$ :

where

$$
p_{x_{2}}=\frac{\sqrt{t_{1}^{2} t_{4}^{2}-t_{2} t_{6}}-t_{3} t_{4}}{t_{5}}
$$

$$
\begin{gathered}
t_{1}=\left[\frac{\left(d_{x 1}-d_{x 2}\right)\left(x_{2}^{3}-x_{1}^{3}\right)}{3\left(x_{2}-x_{1}\right)}+\frac{d_{x 1}\left(x_{2}+x_{1}\right)}{2}-\left(d_{x 1}-d_{x 2}\right) \frac{x_{2}+x_{1}}{x_{2}-x_{1}}-d_{x 1} x_{1}+d_{x 1} x_{1}+\frac{x_{1}^{2}\left(d_{x 1}-d_{x 2}\right)}{x_{2}-x_{1}}\right] ; \\
t_{2}=\left[\frac{\left(d_{x 1}-d_{x 2}\right)\left(x_{2}+x_{1}\right)}{2}-\frac{\left(d_{x 1}-d_{x 2}\right)\left(x_{2}^{3}-x_{1}^{3}\right)}{3\left(x_{2}-x_{1}\right)^{2}}-\frac{d_{x 1}\left(x_{2}+x_{1}\right)}{2}+\left(d_{x 1}-d_{x 2}\right) \frac{x_{2}+x_{1}}{x_{2}-x_{1}}+\right. \\
\left.+d_{x 1}\left(x_{2}-x_{1}\right)-x_{1}\left(d_{x 1}-d_{x 2}\right)+d_{x 1} x_{1}-\frac{x_{1}^{2}\left(d_{x 1}-d_{x 2}\right)}{x_{2}-x_{1}}\right]
\end{gathered}
$$




$$
\begin{gathered}
t_{3}=\left[t_{1}\left(\operatorname{tg} \alpha-f_{x 2}\right)-\frac{d_{x 2}}{4} \frac{1-2 \alpha_{x}}{1+\alpha_{x}}\right] \\
t_{4}=p_{x 1} t_{2}\left(\operatorname{tg} \alpha-f_{x 1}\right)+\sigma_{x 1} \frac{d_{x 1}^{2}}{4} ; \\
t_{5}=t_{3}^{2}+\frac{d_{x 2}^{4}}{16} \frac{9 \alpha_{x}}{\left(1+\alpha_{x}\right)^{2}} ; \\
t_{6}=t_{4}^{2}-\frac{d_{x 2}^{4}}{16} \beta \sigma_{s x}^{2} \frac{1}{1+\alpha_{x}} ;
\end{gathered}
$$

index 1 indicates that this or that parameter belongs to the initial one, and index 2 belongs to the final section of the selected elementary volume of the deformable medium (Fig. 1b).

Taking into account the known values of $p_{x 2}$, proceeding from the plasticity condition (7), i.e. by analogy with (9), the value of normal stresses $\sigma_{x 2}$ can also be determined:

in this case, the tangential contact stresses $\tau_{x 2}$ :

$$
\sigma_{x 2}=\frac{1-2 \alpha_{x 2}}{1+\alpha_{x 2}} p_{x 2}+\sqrt{\frac{\beta \sigma_{s x}^{2}}{1+\alpha_{x}}-p_{x 2}^{2} \frac{9+\alpha_{x}}{\left(1+\alpha_{x}\right)^{2}}}
$$

$$
\tau_{x 2}=p_{x 2} f_{x 2} \text {. }
$$

To determine the deformation parameters, using the dependencies between the main plastic deformation rates $\varepsilon_{l}$, $\varepsilon_{3}$ and the main stresses $\sigma_{1}, \sigma_{2}, \sigma_{3}$, provided by the theory of porous materials flow [22]:

$$
\begin{aligned}
& \dot{\varepsilon}_{1}=3 \lambda\left[\sigma_{1}-(1-2 \alpha)\left(\sigma_{1}+\sigma_{2}+\sigma_{3}\right) / 3\right] ; \\
& \dot{\varepsilon_{3}}=3 \lambda\left[\sigma_{3}-(1-2 \alpha)\left(\sigma_{1}+\sigma_{2}+\sigma_{3}\right) / 3\right] ;
\end{aligned}
$$

speed ratio, and at the same time the corresponding deformation indices ratio $\varepsilon_{l}$ and $\varepsilon_{2}$ can be defined as:

where $\lambda$ - Lagrangian coefficient.

$$
\frac{\dot{\varepsilon}_{1}}{\dot{\varepsilon}_{3}}=\frac{\varepsilon_{1}}{\varepsilon_{3}}=\frac{\sigma_{1}-(1-2 \alpha)\left(\sigma_{1}+\sigma_{2}+\sigma_{3}\right) / 3}{\sigma_{3}-(1-2 \alpha)\left(\sigma_{1}+\sigma_{2}+\sigma_{3}\right) / 3}
$$

Taking into account that in relation to the considered technological scheme (Fig. 1a), by virtue of the accepted assumptions, the following ratios are fulfilled: $\sigma_{2}=\sigma_{3}=p_{x} ; \sigma_{1}=\sigma_{x}$, and the strains in the plane-strain condition should correspond to [22]:

required value of the strain ratio $\varepsilon_{l x} / \varepsilon_{d x}$ can be defined as:

$$
\varepsilon_{2}=\varepsilon_{3}=3 \lambda\left[\sigma_{2}-(1-2 \alpha) \frac{\sigma_{1}+\sigma_{2}+\sigma_{3}}{3}\right]=3 \lambda\left[\sigma_{3}-(1-2 \alpha) \frac{\sigma_{1}+\sigma_{2}+\sigma_{3}}{3}\right]
$$

$$
\frac{\varepsilon^{\prime} l x}{\varepsilon^{\prime} \cdot d x}=\frac{\sigma_{x}-\left(1-2 \alpha_{x}\right) \frac{\sigma_{x}+2 p_{x}}{3}}{p_{x}-\left(1-2 \alpha_{x}\right) \frac{\sigma_{x}+2 p_{x}}{3}}=\frac{3 \sigma_{x}-\left(1-2 \alpha_{x}\right)\left(\sigma_{x}+2 p_{x}\right)}{3 p_{x}-\left(1-2 \alpha_{x}\right)\left(\sigma_{x}+2 p_{x}\right)} .
$$

Proceeding to the selected elementary volume stress-strain state indicators (Fig. 1b):

$$
\begin{gathered}
\varepsilon_{d x}^{*}=\ln \frac{d_{x i 1}^{2}}{d_{x i 2}^{2}} ; \\
\varepsilon_{l x}^{*}=-2 \varepsilon_{d x} \frac{3 \sigma_{x i 2}-\left(1-2 \alpha_{x}\right)\left(\sigma_{x i 2}+2 p_{x i 2}\right)}{3 p_{x}-\left(1-2 \alpha_{x}\right)\left(\sigma_{x i 2}+2 p_{x i 2}\right)}
\end{gathered}
$$

according to the mass conservation condition and taking into account the billet length before rolling $L_{0}$ and after rolling $L_{l}$ :

$$
\gamma_{x i 2} L_{1} \frac{\pi d_{x i 2}^{2}}{4}=\gamma_{x i 1} L_{0} \frac{\pi d_{x i 1}^{2}}{4}
$$

the resulting value of the powder medium relative density within a given volume can be determined as:

$$
\gamma_{x i 2}=\gamma_{x i 1} \frac{d_{x i 1}^{2}}{d_{x i 2}^{2} \exp \varepsilon_{e} e}
$$

It should be pointed out that in a strict setting, the joint solution of equations (1) - (20) is rather lengthy. Therefore, within the framework of this mathematical model based on a numerical recurrent solution, when calculating the coefficients $\alpha_{x 2}$ and $\beta_{x 2}$, we used the value of the relative density corresponding to the initial section of each individual selected elementary volume, i.e.:

$$
\alpha_{x 2}=a\left(1-\gamma_{x 1}\right)^{m} ; \beta_{x 2}=\gamma_{x 1}^{2 n}
$$

Similar to (20), (21), i.e., depending on the current indicators of the strain degree $\varepsilon_{d x}, \varepsilon_{l x}$, and the current indicator of the relative density $\gamma_{x}$, the current value of the yield strength solid phase $\sigma_{s x i}$ can be determined, taking into account the strain change of which is necessary when analyzing the rolling process of sintered powder materials [22]. In this case, the following dependences obtained by the author of the paper [22] for sintered copper powder can be used directly as an analytical description of the functional relationship between the yield strength $\sigma_{s x i}$ and the equivalent strain index $\varepsilon_{e x}$ :

$$
\begin{array}{ll}
\sigma_{s x}=522.2\left(\varepsilon_{e x}+0.007\right)^{0.427} & \text { at } \varepsilon_{e x}<0.23 ; \\
\sigma_{s x}=431.4\left(\varepsilon_{e x}-0.011\right)^{0.279} & \text { at } \varepsilon_{e x}>0.23 .
\end{array}
$$

Actually, the current value of the equivalent strain $\varepsilon_{\mathrm{ex}}$ for the i-th elementary volume can be determined on the basis of the dependences of the paper [22] by numerically integrating the corresponding increments $\Delta \varepsilon_{\mathrm{e} x j}$ in all the previous identified elementary volumes:

$$
\Delta \dot{\varepsilon}_{\mathrm{ex}}=\sqrt{\beta_{x}} /\left(3 \gamma_{x}\right) \cdot \sqrt{4\left(\dot{\varepsilon}_{l x}^{2}-2 \dot{\varepsilon}_{l x} \dot{\varepsilon}_{d x}+\dot{\varepsilon}_{d x}^{2}\right)+\left(\dot{\varepsilon}_{l x} \dot{\varepsilon}_{d x}\right)^{2} / \alpha_{x}}
$$

The direction corresponding to the direction of the rolled composition motion was taken as the vector direction of the used recursive decision scheme, and the following conditions were used as the connection conditions in the transition from the $\mathrm{i}$-th to $(\mathrm{i}+1)$ elementary volume:

$$
x_{1(i+1)}=x_{2 i} ; d_{x 1(i+1)}=d_{x 2 i} ; f_{x 11(i+1)}=f_{x 12 i} ; f_{x 21(i+1)}=f_{x 22 i}
$$




$$
\gamma_{x 1(i+1)}=\gamma_{x 2 i} ; p_{x 1(i+1)}=p_{x 2 i} ; \sigma_{x 1(i+1)}=\sigma_{x 2 i}
$$

where the initial conditions, i.e. geometric and power characteristics for the first elementary volume, corresponded to:

where $\rho_{0}$ - powder density.

$$
\begin{gathered}
x_{1 \mid i=1}=l_{p l} ; d_{x 1 \mid i=1}=d_{0} ; f_{\frac{x 1}{i}=1}=f x 1 \mid i=1_{0} \log \\
\sigma_{x 1 \mid i=1}=0 ; p_{x 1 \mid i=1}=1.155 \sigma_{s x 1 \mid i=1} \sqrt{\frac{1+\alpha_{x 1 \mid i=1}}{1+4 \alpha_{x 1 \mid i=1}} \beta_{x 1 \mid i=1}},
\end{gathered}
$$

Speaking from the perspective of the initial conditions, the calculated values of stresses $\sigma_{x}$, in turn, should be equal to the known stresses of the front tension or support $\sigma_{l}$ (Fig. 1a). The achievement of this condition was ensured by a directed iterative change in the relative length of the forward slip zone on the control work roll $S_{l}=L_{a d v} / L_{p l}$ :

$$
S_{l(k+1)}=S_{l k}+A_{s} \operatorname{sign}\left(\sigma_{x C D k}-\sigma_{1}\right),
$$

where $k$ is the ordinal number of the next iteration cycle; $A_{S}$ is the step of changing the forward slip zone relative length, its value depending on the degree of approach to the desired result, was taken as a variable; $\operatorname{sign}\left\{\sigma_{x C D k}-\sigma_{l}\right\}-$ gradient estimate of the increment direction, corresponding numerically to:

$$
\operatorname{sign}\left\{\sigma_{x C D k}-\sigma_{1}\right\}=\left\{\begin{array}{clll}
1 & \text { for } & \sigma_{x C D k}>\sigma_{1} \\
0 & \text { for } & \sigma_{x C D k} \approx \sigma_{1} \\
-1 & \text { for } & \sigma_{x C D k}<\sigma_{1} .
\end{array}\right.
$$

In general, the set of analytical descriptions presented in this paper, combined with the organization of subsequent numerical integration, made a complete algorithm for one-dimensional mathematical simulation of the pressed flux-cored wire rolling process. The software was developed for the automated calculation of technological modes for the pressed flux-cored wire rolling in a round gauge. Programming is carried out in the linguistic environment MS Visual Studio.

\subsection{Calculation results}

As an example of the obtained mathematical model implementation, Fig. 2 shows the calculated distributions of local and integral characteristics of the pressed flux-cored wire rolling process. The calculation was performed with the following values: the initial diameter of the pressed flux-cored wire was $D_{0}=8.0 \mathrm{~mm}$, the initial relative density was $\gamma_{\mathrm{H}}=0.86$, the radius of the rolls was $R=50 \mathrm{~mm}, a=0.633, m=1.017, n=1.94$.
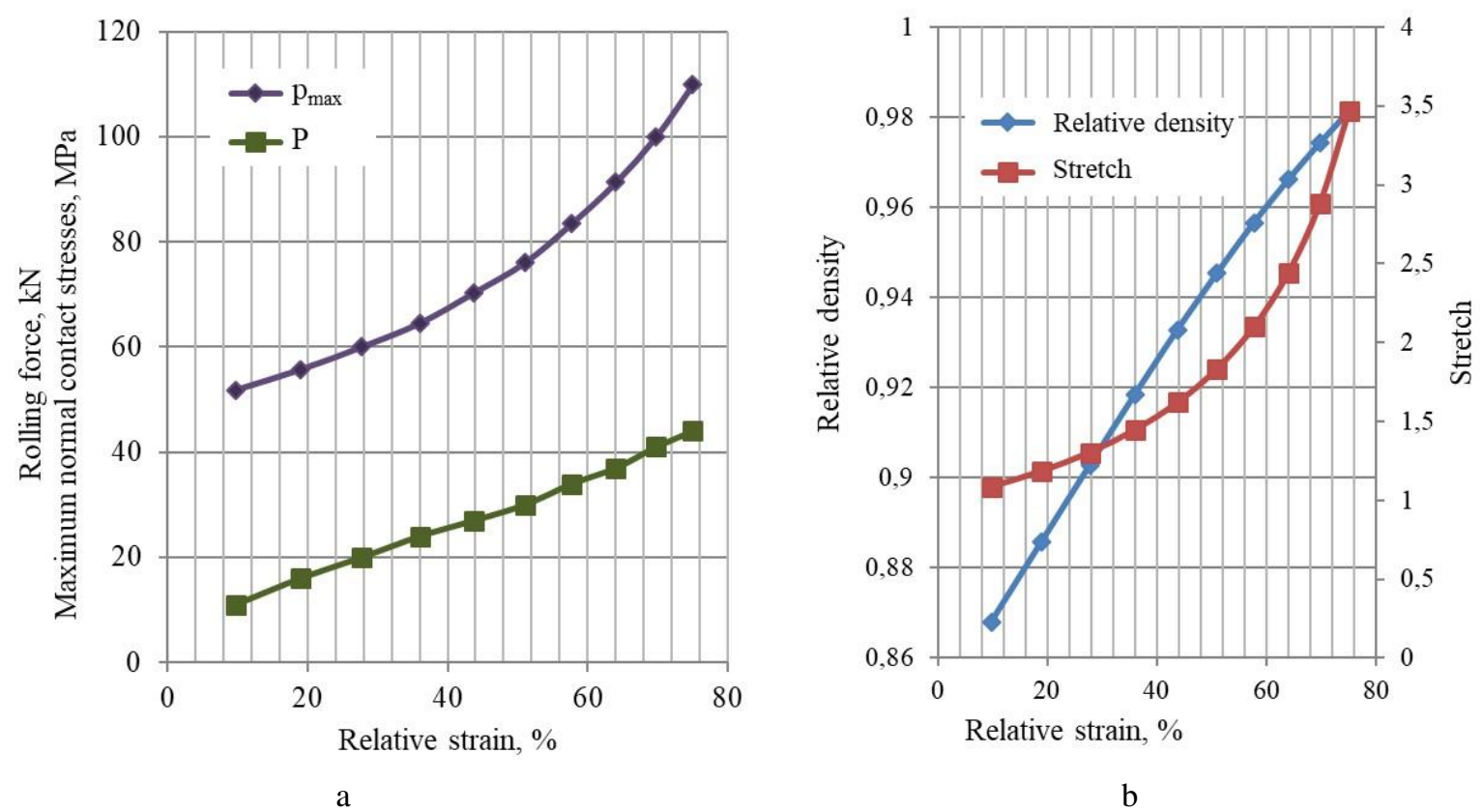

b

Figure 2: Calculated distributions of the flux-cored wire rolling integral characteristics depending on the degree of reduction: rolling force (a) and relative density (b)

\section{Experimental results}

\subsection{Technique of experimental research}

Experimental studies of the rolling process were carried out in order to clarify the initial data for the mathematical model numerical implementation and assess the degree of its reliability, as well as to assess the efficiency of the reduction degree in the rolling process to the structure and basic properties of pressed flux-cored wire.

The pressed flux-cored wire rolling is implemented on a unit including a laboratory mini-mill 100x100 DSEA (Fig. 3) and an analog-to-digital converter ADC SDI-ADC 16-32 connected to the mill using a computer. Experimental studies of energy-power parameters and accuracy of geometric characteristics obtained when rolling a pressed fluxcored wire were carried out on this equipment. 

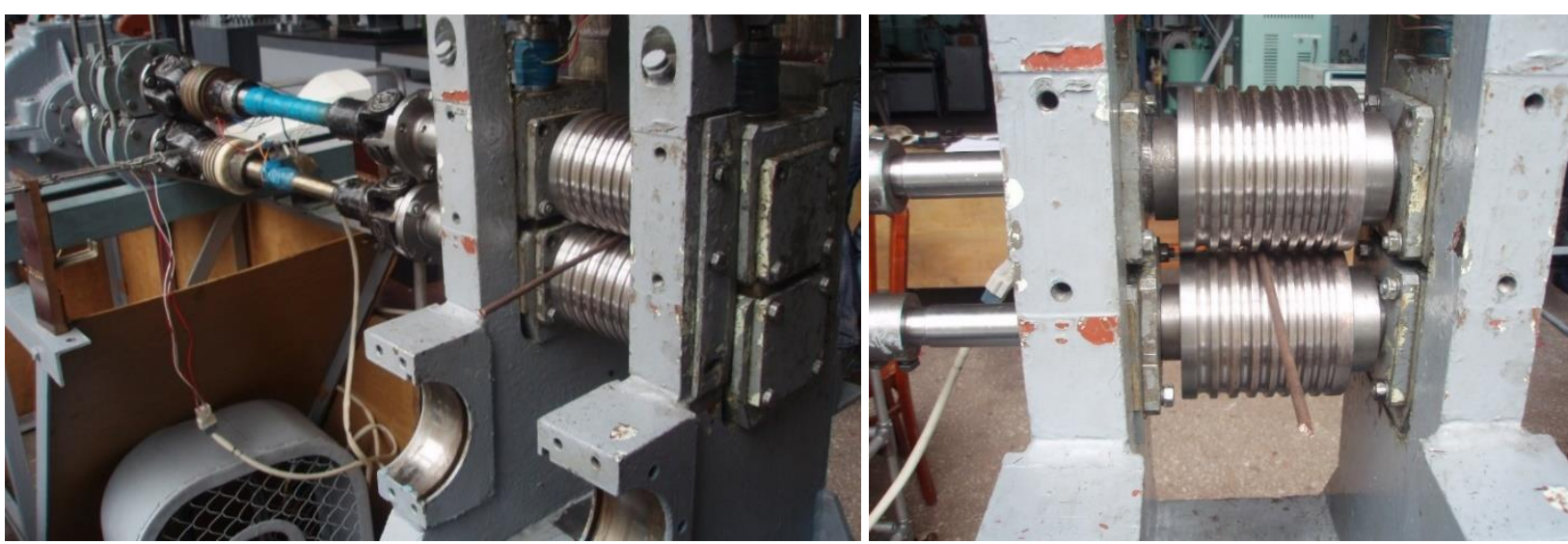

Figure 3: General view of roll mill stand 100 with rolls for rolling flux-cored wire rolling

The working stand of the mini-mill includes the following equipment: lower and upper working rolls, their value of the nominal diameter and barrel length are $100 \mathrm{~mm}$. The work rolls are fixed in journal boxes with angular contact bearings. To balance the upper work roll, between journal boxes rubber packings are installed. The journal boxes of the lower and upper work rolls, in turn, are placed in the window guides of the stands unit and are fixed in the vertical and horizontal planes. The journal boxes of the upper work roll are fixed by means of measuring cells, which are annular elastic elements with strain sensors glued to them. Measuring cells, in turn, are associated with spherical rolling bodies, which are supported by the screw-down gear.

The work rolls themselves are made of steel 40X for eight gauges with a gauge surface hardness of $30 \ldots 40 \mathrm{HS}$ and roughness corresponding to $\sqrt{1.25}$. The diameter of the work rolls is $D_{r}=100 \mathrm{~mm}$, the length of the barrel is $L_{b}=100 \mathrm{~mm}$. The roll drafting was made according to the method [46] used to calibrate the rolls of wire mills, based on the condition that the average stretch per pass does not exceed 1.2:

$$
\lambda=\frac{d_{0}^{2}}{d_{1}^{2}}=1.2
$$

where $d_{0}$-initial value of the pressed flux-cored wire diameter; $d_{l}$ - the value of the diameter after deformation, respectively.

The dimensions of the round gauge $d_{r}$, taking into account the plus and minus allowances (Fig. 4), made:

$$
d_{r}=(1.012 \div 1.015)\left(d_{0}+\frac{\Delta_{1}-\Delta_{2}}{2}\right)
$$

where $\Delta_{1}=0.02 d_{0} ; \Delta_{2}=0.03 d_{0}$ - plus and minus diameter allowance.

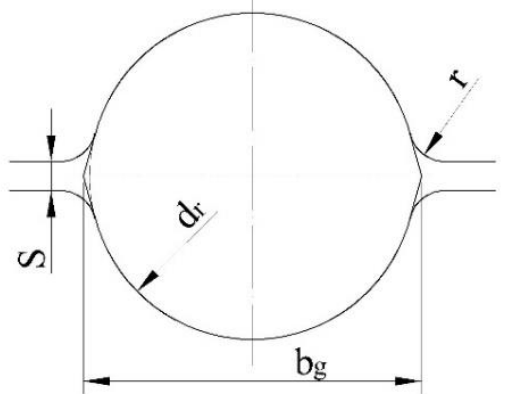

Figure 4: Construction of a finishing gauge for rolling pressed flux-cored wire

In order to ensure a developed high-quality profile, the gauge was made with an allowance (with a discrepancy) on the side walls, based on this, the width of the gauge $b_{g}$ :

the hollow space $S$ between the rolls made:

$$
b_{g}=\left(d_{0}+\Delta_{1}\right)(1.012 \ldots 1.015)
$$

$$
S=(0.08 \ldots 0.15) d_{r}
$$

the sides were rounded with a radius:

$$
r=0,1 d_{g}
$$

Work rolls were made with gauges $d_{g}=8.0 ; 7.3 ; 6.7 ; 6.1 ; 5.6 ; 5.1 ; 4.6 ; 4.2 ;(\mathrm{mm})$.

The roll-to-roll distance was changed using a mechanical-type screw-down gear. When conducting experimental studies, the following technological parameters were recorded:

- $\quad$ the value of the rolling power at each gauge, which was measured by means of measuring cells installed under the mill screws;

- the rolling torque on the driven rolls, which was recorded by resistance strain sensors glued to the bodies of each of the universal spindles in a bridge circuit;

- $\quad$ the original diameter of the pressed flux-cored wire $d_{0}$ and the diameter after each pass (strain) $d_{l}$;

- $\quad$ the original length of pressed flux-cored wire and drawing after each pass. 
In the course of rolling, in each gauge, the reduction was carried out with different relative deformations, which varied in the range $\varepsilon=0.15-0.75$. The process proceeded without the use of rolling lubricant. For each subsequent gauge and corresponding reduction, the rolling force $P$ and the moments on the upper and lower rolls were measured.

All recorded parameters, current in time, were recorded using an analog-to-digital converter ADC SDI-ADC 1632 with a computer. The power source was a storage battery with the $12 \mathrm{~V}$ nominal voltage. The use of this sixteenbit analog-to-digital converter allowed to digitize the input signal with a frequency of $100 \mathrm{kHz}$, with a hundredfold amplification of the signal.

To interpret the obtained oscillograms by force and by the moment of rolling, calibration charts were built, and the calibration constant was determined. Calibration of the force and rolling moment meters was performed before and after the rolling process. Measuring cells installed on the mill between the mill screws and the journal boxes of the work rolls were calibrated using a hydraulic press, on which they were loaded with a force $P$, the value of which was known based on the working fluid pressure in the system recorded by the pressure gauge. The calibration of the spindles with strain gauges glued to them was carried out using a lever, which was loaded with a known load.

After each pass by the obtained pressed flux-cored wire, the geometric characteristics were measured, they are: the values of the diameter $d_{0}\left(d_{1}\right)$ were measured at three points using a micrometer (with a scale division of $0.01 \mathrm{~mm}$ ), and drawing $\lambda$ was measured using a ruler (with a scale division of $1.0 \mathrm{~mm}$ )

Also, after each pass, the relative density of the pressed flux-cored wire was measured. Determination of the density of molded powder materials is regulated by GOST 18898-83 and provides for the use of calculation and hydrostatic methods.

Determination of the obtained pressed flux-cored wire samples density by the calculation method: the essence of the method is to measure the volume and mass of the sample. The following equipment was used for the tests: electronic weigher AR 3130 (Ohaus, USA) with an accurate within $0.001 \mathrm{~g}$; measuring tool - micrometers with a scale division of $0.01 \mathrm{~mm}$ (GOST 6507-90); vernier caliper with a scale division of $0.1 \mathrm{~mm}$.

To determine the density, the sample was weighed in air with an accuracy within $0.001 \mathrm{~g}$, and its main dimensions were measured, by which the volume was calculated.

The sample density $\gamma$ in $\mathrm{g} / \mathrm{cm}^{3}$ was calculated by the formula:

$$
\gamma=\frac{m}{V}
$$

where $m$ - sample weight, $\mathrm{g} ; V$ - sample volume, $\mathrm{cm}^{3}$

The relative density of the samples in percent was determined by the formula:

$$
\rho=\frac{\gamma}{\gamma_{\mathrm{M}}} \cdot 100,
$$

where $\gamma_{M}$ - theoretical density of a non-porous material given composition (copper M1 $-\gamma_{M}=8.3 \mathrm{~g} / \mathrm{cm}^{3}$ )

Determination of the obtained pressed flux-cored wire samples density by the calculation method: the essence of the method is to measure the mass of the product in air and in distilled water. This method was used to control the measurement of the pressed flux-cored wire samples density by the calculation method.

A specially designed unit was used for the measurement (Fig. 5). The use of the AR 3130 electronic analytical balance (Ohaus, USA) in this unit allows weighing with an accuracy of $0.001 \mathrm{~g}$. Before each weighing, the zero point of the balance was checked. The sample was suspended to the special balance pickup on a thin $(0.1 \mathrm{~mm})$ monofilament. The length of the monofilament was chosen so that the sample, when lifting the measuring cylinder with distilled water, was freely immersed to a depth of at least $10 \mathrm{~mm}$ from the surface of the liquid. To measure the density, the distilled water (GOST 6709-72) was used with the addition of 1-2 drops of triethanolamine, a substance that reduces the surface tension of a liquid, that protects the samples from the settling of air bubbles on them.

The tests were carried out in the following way. Samples of pressed flux-cored wire after each gauge with a length of $l=20 \mathrm{~mm}$ were weighed in air. After that, the surface pores were closed by covering the surface with a thin layer of petroleum jelly (GOST 3582-84). Petroleum jelly was applied to the surface of the product, in a thin layer, followed by rubbing. After processing, the sample was weighed in air and in water.

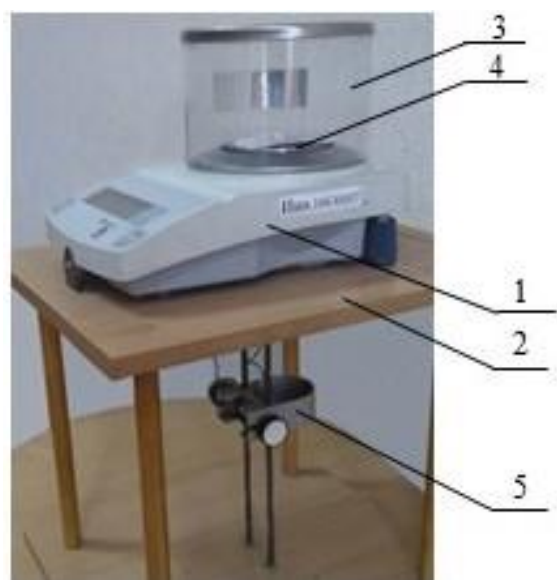

Figure 5: Unit for hydrostatic weighing the samples (1 - electronic analytical balance, 2 - stand, 3 - measuring cylinder, 4 - sample, 5 - supporting block) 
When weighing in water, the formation of air bubbles on the surface of the samples is not permissible. When bubbles appeared, the samples were removed from the water, dried, processed to close the pores, and weighed again in air and water.

The density $\rho$ of the pressed flux-cored wire samples was calculated by the formula:

$$
\rho=\frac{m}{m_{\mathrm{a}}-m_{\mathrm{w}}-\left[\left(m_{\mathrm{a}}-m\right) \frac{\rho_{w}}{\rho}\right]+m_{\mathrm{wire}}} \rho_{w},
$$

where $m$ is the mass of the sample, $\mathrm{g} ; m_{a}$ is the mass of the coated sample, weighed in air, $\mathrm{g} ; m_{w}$ is the mass of the sample suspended in water, $\mathrm{g} ; m_{\text {wire }}$ is the weight of the wire during weighing, $\mathrm{g} ; \rho_{w}$ is the density of water, $\mathrm{g} / \mathrm{cm}^{3}$ (see Table 1 ).

Table 1

Dependence of the distilled water density on temperature

\begin{tabular}{|l|l|l|l|l|l|l|}
\hline Water temperature, ${ }^{\circ} \mathrm{C}$ & 17 & 18 & 19 & 20 & 21 & 22 \\
\hline Water density $\rho_{w}, \mathrm{~g} / \mathrm{cm}^{3}$ & 0.9988 & 0.9986 & 0.9984 & 0.9982 & 0.9980 & 0.9972 \\
\hline
\end{tabular}

The density of petroleum jelly was taken equal to $0.830 \mathrm{~g} / \mathrm{cm}^{3}$, the density of the samples was calculated with an accuracy of $0.001 \mathrm{~g} / \mathrm{cm}^{3}$. When determining the density of the pressed flux-cored wire, the error between the calculated and hydrostatic methods was not more than $5 \%$.

\subsection{Results of experimental studies}

The results of pressed flux-cored wire rolling process study are presented in Table 2. Graphical interpretation of experimental pressed flux-cored wire rolling process study, supplemented with calculated dependencies, obtained using a mathematical model, is shown in Figure 6.

Fig. 6a shows the experimental and calculated distributions of the relative density $\gamma$ over the passes. From the analysis of the obtained experimental data, it can be seen that as the diameter decreases, i.e. the degree of reduction increases, the relative density increases from 0.86 to 0.93 and approaches the density of the monometal. The error in comparing the calculated and experimental distributions of the relative density along the passes is within the acceptable range from $0.5 \%$ to $5 \%$.

Fig. $6 \mathrm{~b}$ shows the experimental and calculated distributions of the drawing $\lambda$ over the passes. From the analysis of the obtained experimental data, it can be seen that with an increase in the degree of reduction, there is an increase in the drawing along the length of the pressed flux-cored wire and makes 3.23. In this case, the error in comparing the calculated and experimental distributions of the drawings along the length was from $-4 \%$ to $9 \%$. The drawing incrementation along the passes is increased the most significantly after reaching the reduction strain of $45 \%$, which is associated with the achievement of the relative density maximum value due to plastic strain and partial slipping of particles relative to each other. Ultimately, the volume equality condition and analysis of the obtained calculated and experimental distributions of the relative density and the pressed flux-cored wire drawing along the passes, shown in Fig. $6 a$, b, resulted in the fact that the elongation strain $\varepsilon_{L}$ was $77 \%$, and the seal strain $\varepsilon_{d}$ was $23 \%$. Such a ratio of strain is possible in the case of strain in metal grits volume with the plastic flow of the metal for its shell, that affected the location of the pressed flux-cored wire non-metallic component.

Fig. 6c depicts the experimental distributions of the pressed flux-cored wire rolling force over the passes. Comparison of the obtained experimental and calculated distributions shows that the discrepancy between them is in the range from $0 \%$ to $5 \%$.

The above-mentioned confirms the reliability of the developed mathematical model and the possibility of its use to solve optimization problems for the development of technological modes for the manufacture of pressed flux-cored wire.

Table 2

Results of experimental and theoretical studies of rolling flux-cored wire in round gauges

\begin{tabular}{|c|c|c|c|c|c|c|c|c|c|}
\hline \multirow{3}{*}{ \# } & \multirow[b]{2}{*}{$d_{0}$} & \multirow[b]{2}{*}{$d_{1}$} & \multirow[b]{2}{*}{$\gamma_{0}$} & \multicolumn{6}{|c|}{ Theoretical } \\
\hline & & & & $\gamma_{1}$ & $\varepsilon_{l}$ & $\varepsilon_{d}$ & $p_{\max }$ & $P$ & $M$ \\
\hline & $m m$ & $m m$ & - & - & - & - & $M P a$ & $k N$ & $\mathrm{Nm}$ \\
\hline 1 & 8.1 & 8 & 0.8685 & 0.91 & 74.59 & 2.48 & 197 & 10.23 & 21.98 \\
\hline 2 & 8 & 7.7 & 0.91 & 0.911 & 29.18 & 7.64 & 119 & 10.32 & 19.08 \\
\hline 3 & 7.7 & 7.45 & 0.911 & 0.915 & 43.77 & 6.6 & 171 & 11.07 & 10.25 \\
\hline 4 & 7.45 & 6.8 & 0.915 & 0.92 & 30.87 & 18.26 & 104 & 12.78 & 31.95 \\
\hline 5 & 6.8 & 6 & 0.92 & 0.93 & 58.98 & 25.03 & 118 & 13.85 & 33.33 \\
\hline 6 & 6 & 5.6 & 0.93 & 0.931 & 41.27 & 13.8 & 182 & 12.88 & 20.17 \\
\hline 7 & 5.6 & 5.4 & 0.932 & 0.94 & 14.19 & 7.27 & 124 & 6.2 & 11.48 \\
\hline 8 & 5.4 & 4.5 & 0.94 & 0.95 & 133.66 & 36.46 & 136 & 12.63 & 30.01 \\
\hline
\end{tabular}




\begin{tabular}{|r|r|r|r|r|r|}
\hline \multirow{3}{*}{$\#$} & \multicolumn{6}{|c|}{ Experimental } \\
\cline { 2 - 6 } & \multicolumn{1}{|c|}{$\gamma_{1}$} & \multicolumn{1}{l|}{$\mathrm{P}$} & \multicolumn{1}{l|}{$\mathrm{M}$} & \multicolumn{1}{l|}{$\varepsilon_{l}$} & \multicolumn{1}{l|}{$\varepsilon_{d}$} \\
\cline { 2 - 6 } & \multicolumn{1}{|l}{$\mathrm{kN}$} & $\mathrm{Nm}$ & \multicolumn{1}{l}{-} & \multicolumn{1}{l}{} \\
\hline 1 & 0.91 & 12 & 26 & 1.05 & 0.18 \\
\hline 2 & 0.911 & 12.2 & 25 & 1.6 & 0.31 \\
\hline 3 & 0.915 & 13 & 26 & 2 & 0.43 \\
\hline 4 & 0.92 & 13.6 & 24 & 2.7 & 0.52 \\
\hline 5 & 0.93 & 14 & 27 & 3.7 & 0.6 \\
\hline 6 & 0.931 & 13.2 & 20 & 4.5 & 0.67 \\
\hline 7 & 0.93 & 13.2 & 27 & 5.4 & 0.72 \\
\hline 8 & 0.933 & 13.2 & 27 & 5.4 & 0.72 \\
\hline
\end{tabular}
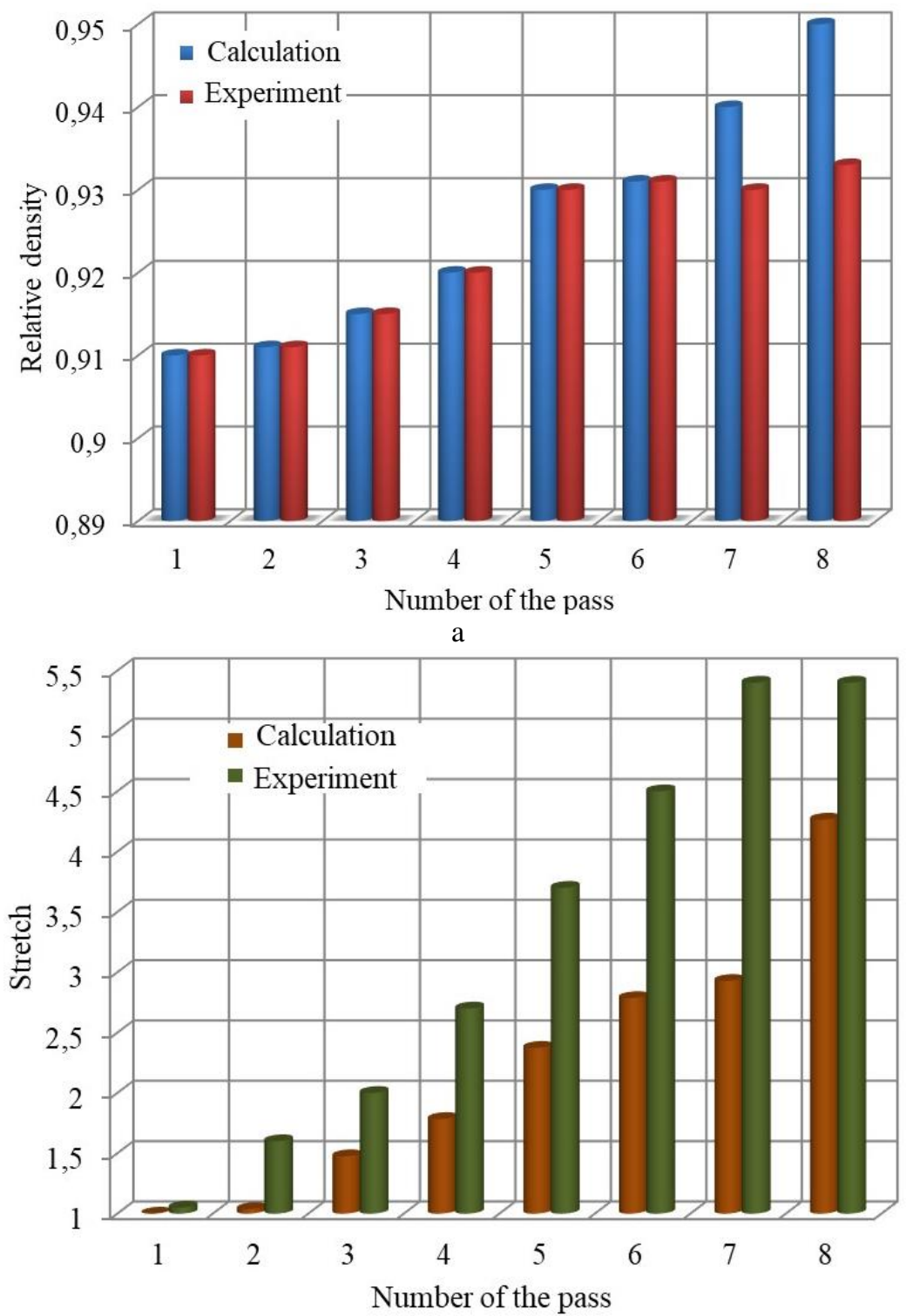


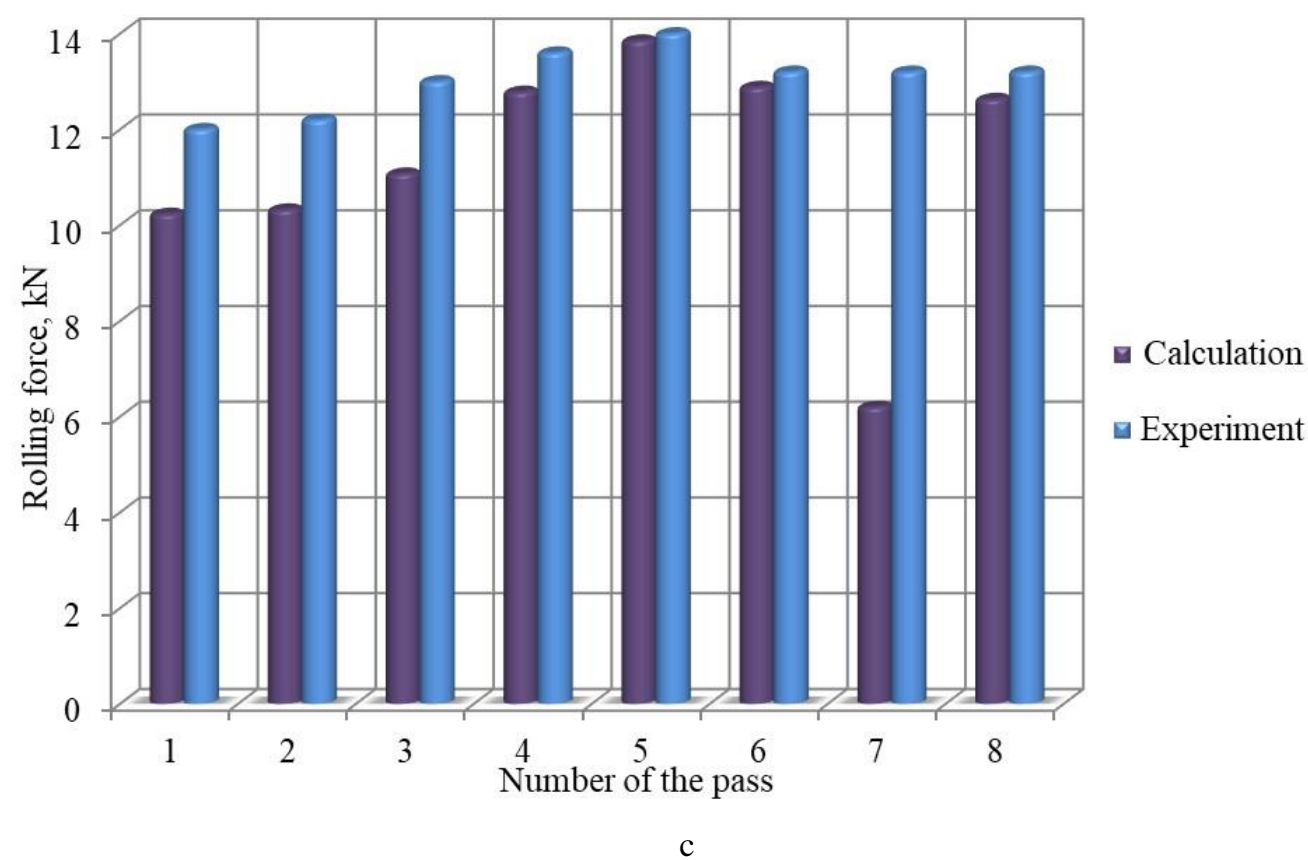

Figure 6: Theoretical and experimental distributions of the integral characteristics for the flux-cored wire rolling through passes: relative density (a), drawing (b), rolling force (c)

\section{Pressed flux-cored wire production optimization}

The main task in the design of the pressed flux-cored wire rolling technological modes is to obtain the required diameter with a given density, which is achieved due to the optimal calibration of the work rolls. When solving this problem, it is necessary to know the number of passes and reduction in each of them, that is, it is necessary to know the main integral characteristics of the process, such as the final relative density of the powder, wire elongation and energy-power parameters. Since these parameters depend on the conditions for the process implementation, the problem comes down to solving the optimization plan issue.

To determine the optimal calibration of the rolls, an automated design of technological modes for rolling pressed flux-cored wire in a round gauge was carried out. As design criteria, we used the required wire diameter $\left[d_{l}\right]$, the average drawing along the passes $\lambda$, or the uniform distribution of technological loads $P$ along the passes. The relative deformation $\varepsilon$ in each pass was used as a design parameter. The previously considered mathematical model of the rolling flux-cored wire in a round gauge was used as the target functions.

The solution was an iterative procedure to determine the reduction in each pass depending on the required technological parameters. When determining the reductions from the condition of uniform loading according to rolling force:

$$
d_{1 i(k+1)}=d_{1 i_{k}}+A_{d} \operatorname{sign}\{[P]-P\}_{k},
$$

where $k$-the ordinal number of the iterative solution procedure next cycle; $A_{S_{l o n}}$ - the step of changing the relative length of the forward slip zone, the value of which was taken as a variable, depending on the degree of approach to the desired result: $A_{d}=10^{-5}-10^{-3} ; A_{d}=10^{-5}-10^{-3} ; \operatorname{sign}\left\{\left.P_{n x 2 i}\right|_{i=K_{R}}-P_{n 1}\right\}$ - sign function corresponding to:

$$
\operatorname{sign}\left\{\left.P_{n \times 2 i}\right|_{i=K_{R}}-P_{n 1}\right\}=\left\{\begin{array}{ccc}
+1 & \text { at } & \left.P_{n \times 2 i}\right|_{i=K_{R}}>P_{n 1} ; \\
0 & \text { at } & \left.P_{n \times 2 i}\right|_{i=K_{R}} \approx P_{n 1} \\
+1 & \text { at } & \left.P_{n \times 2 i}\right|_{i=K_{R}}<P_{n 1}
\end{array}\right.
$$

Determination of reductions from the condition of uniform drawing along the passes allows uniform strain of the pressed flux-cored wire, thereby reducing the likelihood of its destruction during rolling. Analytically, the optimization condition for this criterion can be expressed as follows:

$$
d_{1 i(k+1)}=d_{1 i_{k}}+A_{d} \operatorname{sign}\{[\lambda]-\lambda\}_{k},
$$

where $\operatorname{sign}\left\{\left.\lambda_{n \times 2 i}\right|_{i=K_{R}}-\lambda_{n 1}\right\}-$ sign function corresponding to:

$$
\operatorname{sign}\left\{\left.\lambda_{n \times 2 i}\right|_{i=K_{R}}-\lambda_{n 1}\right\}=\left\{\begin{array}{ccc}
+1 & \text { at } & \left.\lambda_{n \times 2 i}\right|_{i=K_{R}}>\lambda_{n 1} \\
0 & \text { at } & \left.\lambda_{n \times 2 i}\right|_{i=K_{R}} \approx \lambda_{n 1} \\
+1 & \text { at } & \left.\lambda_{n x 2 i}\right|_{i=K_{R}}<\lambda_{n 1}
\end{array}\right.
$$

When determining the optimal rolling modes, the method of targeted enumeration was used. The enlarged block diagram of this solution algorithm is shown in Fig. 7. On its basis, software was developed in the MS Visual Studio environment for the automated design of pressed flux-cored wire rolling technological modes.

As an example, the Table 3 shows the calculated values of technological parameters, which allow to determine the necessary calibration of the rolls from the condition of uniform drawing along the passes, which allows uniform strain of the pressed flux-cored wire, thereby increasing the relative density and reducing the likelihood of its 
destruction during rolling. Table 4 shows the reduction modes calculated from the conditions of the equipment uniform loading, which allows, for example, with the same rolling force, to reduce the elastic strain of the rolling mill working stand, thereby reducing the opening of the gauge and increasing the quality of the obtained pressed flux-cored wire.

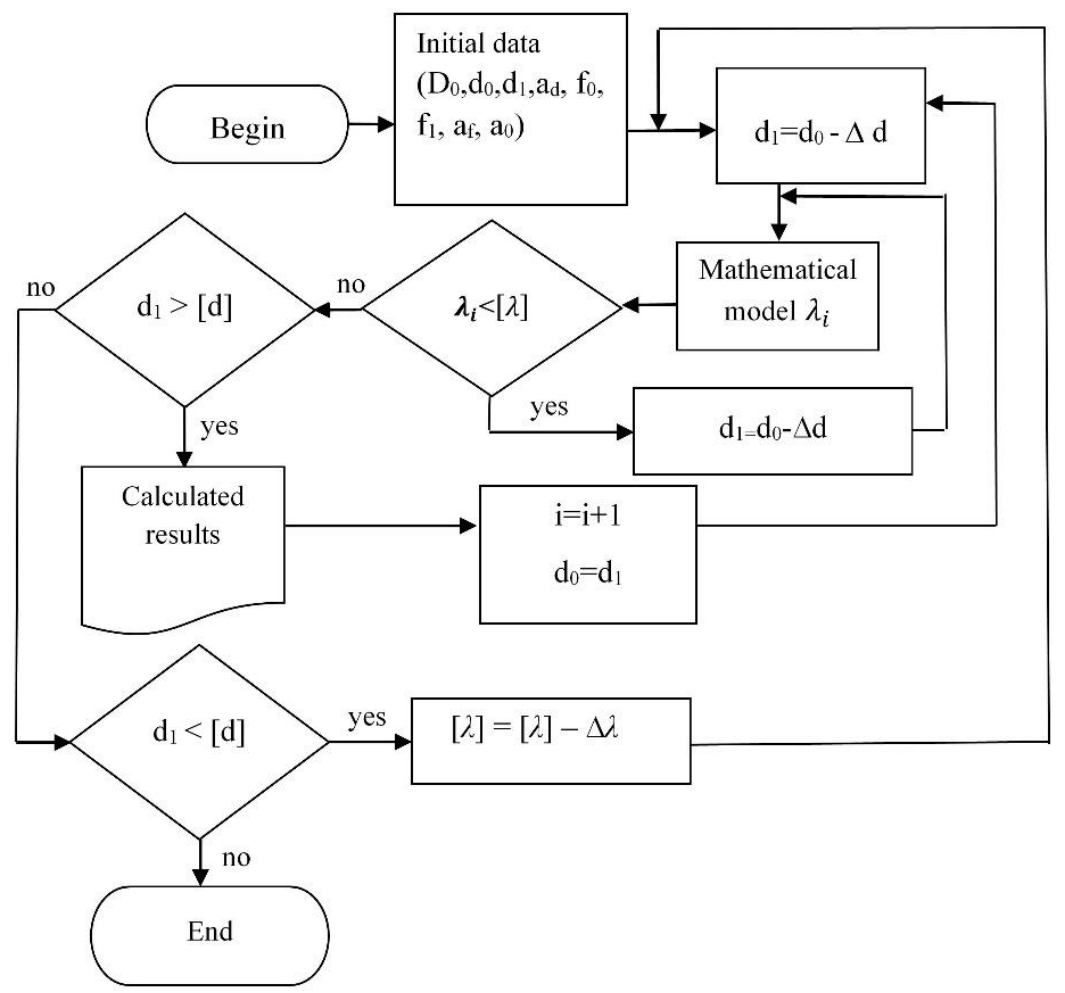

Figure 7: The enlarged block diagram of the algorithm for solving the automation process when rolling pressed flux-cored wire

Table 3

Results of computer-aided design for rolling pressed flux-cored wire rolling technological modes from the condition of uniform drawing along the passes

\begin{tabular}{|l|l|l|l|l|l|l|l|l|l|}
\hline \multicolumn{1}{|c|}{ Pass } & \multicolumn{1}{c|}{$d_{0}$} & \multicolumn{1}{c|}{$d_{l}$} & $\gamma_{1}$ & $\lambda$ & $p_{\max }$ & $P$ & $M$ & $N$ & $A_{s p}$ \\
\hline & $\mathrm{mm}$ & $\mathrm{mm}$ & - & - & $\mathrm{MPa}$ & $\mathrm{kN}$ & $\mathrm{Nm}$ & $\mathrm{W}$ & $\mathrm{MJ} / \mathrm{t}$ \\
\hline 1 & 8.0 & 7.3 & 0.8801 & 1.1504 & 54.4 & 15 & 92 & 55 & 5.92 \\
\hline 2 & 7.3 & 6.7 & 0.9054 & 1.1509 & 59.1 & 14 & 83 & 49 & 6.1 \\
\hline 3 & 6.7 & 6.2 & 0.9261 & 1.1508 & 63.3 & 13 & 73 & 44 & 6.23 \\
\hline 4 & 6.2 & 5.7 & 0.9427 & 1.1507 & 66.8 & 12 & 60 & 36 & 5.88 \\
\hline 5 & 5.7 & 5.3 & 0.956 & 1.1512 & 70.2 & 11 & 57 & 34 & 6.47 \\
\hline 6 & 5.3 & 4.9 & 0.9665 & 1.1536 & 73.1 & 10 & 51 & 30 & 6.66 \\
\hline 7 & 4.9 & 4.6 & 0.9747 & 1.1541 & 75.2 & 9 & 41 & 25 & 6.22 \\
\hline 8 & 4.6 & 4.5 & 0.9758 & 1.0246 & 71.5 & 4 & 11 & 7 & 1.84 \\
\hline
\end{tabular}

Table 4

Results of computer-aided design for rolling pressed flux-cored wire technological modes from the condition of uniform loading along the passes

\begin{tabular}{|l|l|l|l|l|l|l|l|l|l|}
\hline \multicolumn{1}{|c|}{ Pass } & \multicolumn{1}{c|}{$d_{0}$} & \multicolumn{1}{c|}{$d_{l}$} & $\gamma_{1}$ & $\lambda$ & $p_{\max }$ & \multicolumn{1}{c|}{$P$} & \multicolumn{1}{c|}{$M$} & $N$ & $A_{s p}$ \\
\hline & $\mathrm{mm}$ & $\mathrm{mm}$ & - & - & $\mathrm{MPa}$ & $\mathrm{kN}$ & $\mathrm{Nm}$ & $\mathrm{W}$ & $\mathrm{MJ} / \mathrm{t}$ \\
\hline 1 & 8.0 & 7.6 & 0.8703 & 1.0966 & 52.2 & 12 & 60 & 36 & 3.7 \\
\hline 2 & 7.6 & 7.1 & 0.8898 & 1.1046 & 55.7 & 12 & 64 & 38 & 4.38 \\
\hline 3 & 7.1 & 6.7 & 0.9085 & 1.1166 & 59.2 & 12 & 60 & 36 & 4.54 \\
\hline 4 & 6.7 & 6.2 & 0.9266 & 1.1339 & 63 & 12 & 61 & 36 & 5.22 \\
\hline 5 & 6.2 & 5.7 & 0.9436 & 1.1549 & 67.2 & 12 & 66 & 39 & 6.51 \\
\hline 6 & 5.7 & 5.2 & 0.9594 & 1.1894 & 71.7 & 12 & 68 & 40 & 7.89 \\
\hline 7 & 5.2 & 4.6 & 0.9734 & 1.2395 & 76.8 & 12 & 69 & 41 & 9.89 \\
\hline 8 & 4.6 & 4.5 & 0.9759 & 1.0541 & 72.8 & 5 & 17 & 10 & 2.66 \\
\hline
\end{tabular}




\section{Discussion}

The analysis of the developed mathematical model implementation resulted in the following. The growth of the process integral characteristics, such as force, moment, maximum contact stresses, drawing, relative density, increase with the reduction degree addition (Fig. 3). So, with the pressed flux-cored wire reduction degree increase from $\varepsilon=$ $10 \%$ to $\varepsilon=75 \%$, the rolling power $P$ increases by $75 \%$, and the maximum contact stresses $p_{\max }$ increase by $54 \%$ (Figure $2 \mathrm{a}$ ). The relative density $\gamma$ increased by $10 \%$, and the drawing $\lambda$ increased by $71 \%$ (Figure $2 \mathrm{~b}$ ). These dependencies can be used to select the most rational rolling modes, on conditions that the required parameters of the finished wire are provided with a minimum level of energy costs.

The presented results of the calculated distributions of the pressed flux-cored wire rolling integral indicators are of a rather complex non-monotonic nature. This fact, in turn, confirms the need for a more complete consideration of the whole set of factors inherent in this technological scheme, that, in particular, was carried out on the basis of the presented mathematical model applied to the pressed flux-cored wire manufacturing.

The adequacy of the developed mathematical model was verified by experiment on the mill 100, at the laboratory of the Department of AMM DSEA. The analysis of the obtained results showed that the error in theoretical density calculations did not exceed $10 \%$. This confirms the possibility of using a mathematical model in the design of technology and equipment for the implementation of the pressed flux-cored wire rolling in round gauges. Rolling was performed at the following initial values: the initial diameter of the pressed flux-cored wire was $8.0 \mathrm{~mm}$, the initial relative density was $\gamma_{0}=0.88$, and the radius of the rolls was $R=50 \mathrm{~mm}$.

From the analysis of these distributions, it is clear that the solving optimization problem resulted in a uniform distribution of the drawing over the passes, that will allow the process to be carried out with a uniform deformation intensity and reduce the probability of wire fracture during rolling. On the other hand, with such a process, a decrease in the rolling power is observed, which, if the rigidity of the system is insufficient, can lead to the ridges formation along the edges of the billet in the first passes. Rational option in the latter case is the use of a generalized optimality criterion.

Thus, using the developed software, it is possible to solve the problems of the optimization plan for various requirements for the production technology. For example, to determine the required initial wire diameter depending on the number of passes, to determine the required initial powder density at a given final density, to determine the modes of pressed flux-cored wire production at a given final diameter, etc.

\section{Conclusions}

1. A one-dimensional mathematical model of the pressed flux-cored wire rolling process is developed. It is based on the numerical recurrent solution of the static equilibrium condition of the selected elementary metal volume in the zone of its plastic strain, that allows calculating local and integral indicators.

2. The error of the calculated data and experimental studies is not more than $10 \%$, that indicates the adequacy of the developed mathematical model for the pressed flux-cored wire rolling and the possibility of its use for solving optimization problems in computer-aided design of both equipment and technological modes.

3. Computer-aided design of the pressed flux-cored wire rolling in a round gauge was carried out and resulted in the optimal technological modes of pressed flux-cored wire rolling with diameters from $8 \mathrm{~mm}$ to $4.2 \mathrm{~mm}$ to be determined on the basis of drawings equality along the passes and the increased quality of pressed flux-cored wire.

4. From a practical point of view, the results of rolling technological modes automated design allow to determine all the initial parameters of the process to obtain a given standard size of pressed flux-cored wire.

\section{Disclosure}

The submission of the authors' paper implies that it has not been previously published, that it is not under consideration for publication elsewhere, and that it will not be published elsewhere in the same form without the written permission of the editors.

\section{Conflict of Interests}

The authors Eduard P. Gribkov, Sergey O. Malugin, Svetlana S. Hurkovskaya, Elena V. Berezshnaya and Dmytro V. Merezhko declare that there is no conflict of interests regarding the publication of this paper.

\section{Authors' contributions}

All authors participated in the design of this work and performed equally. All authors read and approved the final manuscript.

\section{Compliance with ethical guidelines}

Competing interests. The authors declare that they have no competing interests. 


\section{REFERENCES}

[1] Buntoeng Srikarun, Hein Zaw Oo, Salita Petchsang, Prapas Muangjunburee (2019) The effects of dilution and choice of added powder on hardfacing deposited by submerged arc welding. Wear 424-425: 246254. https://doi.org/10.1016/j.wear.2019.02.027

[2] Tušek J, Suban M (2003) High-productivity multiple-wire submerged-arc welding and cladding with metal-powder addition. Journal of materials processing technology 133(1-2): 207-213. https://doi.org/10.1016/S0924-0136(02)00235-2

[3] Brass W, Scholz R (2015). U.S. Patent No. 9,162,305. Washington, DC: U.S. Patent and Trademark Office.

[4] Hoefer K, Haelsig A, Mayr P (2018) Arc-based additive manufacturing of steel componentsComparison of wire-and powder-based variants. Welding in the World 62(2): 243-247. https://doi.org/10.1007/s40194-017-0527-9

[5] Brandl E, Baufeld B, Leyens C, Gault R (2010) Additive manufactured Ti-6Al-4V using welding wire: comparison of laser and arc beam deposition and evaluation with respect to aerospace material specifications. Phys Procedia 5: 595-606. https://doi.org/10.1016/j.phpro.2010.08.087

[6] Zahiri R, Sundaramoorthy R, Lysz P, Subramanian C (2014) Hardfacing using ferro-alloy powder mixtures by submerged arc welding. Surface and Coatings Technology 260: 220-229. https://doi.org/10.1016/j.surfcoat.2014.08.076

[7] Ma Y, Gao Z, Qi Y, Zhang X, Wang L, Zhang Z, Wang D (2009) Fabrication and characterization of iron pnictide wires and bulk materials through the powder-in-tube method. Physica C: Superconductivity 469(912): 651-656. https://doi.org/10.1016/j.physc.2009.03.024

[8] Ma Y, Wang L, Qi Y, Gao Z, Wang D, Zhang X (2010) Development of powder-in-tube processed iron pnictide wires and tapes. IEEE Transactions on applied superconductivity: 21(3): 2878-2881. http://dx.doi.org/10.1109/TASC.2010.2079311

[9] Yong Wang, Ying Qiao Zhang, Bao Wang, Zhi Jun Wang (2013) Study on Metal Transfer and Welding Spatter Characteristics of Basic Flux Cored Wire. Applied Mechanics and Materials 477-478: 1369-1372. https://doi.org/10.4028/www.scientific.net/AMM.477-478.1369

[10] Liu HY, Li ZX, Li H, Shi YW (2008) Study on metal transfer modes and welding spatter characteristics of self-shielded flux cored wire. Science and Technology of Welding and Joining 13(8): 777780. https://doi.org/10.1179/174329308X380354

[11] Souvik Das, Sandip Talukdar, Anup Kumar, Goutam Mukhopadhyay (2020) Metallurgical investigation of welding wire rod grade during processing. Engineering Failure Analysis 118: 1-9. https://doi.org/10.1016/j.engfailanal.2020.104884

[12] Teoh LL (1995) Thermo-mechanical processing and microstructure of microalloyed steel bar and wire rod products. Journal of Materials Processing Technology 48 (1-4): 475-481. https://doi.org/10.1016/0924-0136(94)01685-T

[13] Fattahi M, Rostami M, Amirkhanlu F, Arabian N, Ahmadi E, Moayedi H (2019) Fabrication of aluminum TIG welding filler rods reinforced by $\mathrm{ZrO} 2 /$ reduced graphene oxide hybrid nanoparticles via accumulative roll bonding. Diamond and Related Materials 99: 1-8. https://doi.org/10.1016/j.diamond.2019.107518

[14] Bhattacharya R, Jha G, Kundu S, Shankar R, Gope N (2006) Influence of cooling rate on the structure and formation of oxide scale in low carbon steel wire rods during hot rolling. Surface and Coatings Technology 201 (3-4): 526-532. https://doi.org/10.1016/j.surfcoat.2005.12.014

[15] Gehling, T, Treutler K, Wesling V (2019) Targeted influence on the weld strength of high-strength fine-grain structural steels in the GMA welding process through functionalized weld material surfaces. Welding in the World 63(3): 783-792. https://doi.org/10.1007/s40194-019-00707-2

[16] Es-Saheb MH, Albedah A, Benyahia F (2011) Diametral compression test: validation using finite element analysis. Int J Adv Manuf Technol 57(5-8): 501-509. https://doi.org/10.1007/s00170-011-3328-0

[17] Hrairi M, Chtourou H, Gakwaya A, Guillot M (2011) Modeling the powder compaction process using the finite element method and inverse optimization. Int J Adv Manuf Technol 56(5-8): 631-647. https://doi.org/10.1007/s00170-011-3211-z

[18] Keshavarz S, Khoei AR, Molaeinia Z (2013) Genetic algorithm based numerical optimization of powder compaction process with temperature-dependent cap plasticity model. Int J Adv Manuf Technol 64(58): 1057-1072. https://doi.org/10.1007/s00170-012-4053-Z

[19] Tseng HC, Hung C ,Huang CC (2010) An analysis of the formability of aluminum/copper clad metals with different thicknesses by the finite element method and experiment. Int J Adv Manuf Technol 48 (912):1029-1036. https://doi.org/10.1007/s00170-009-2446-4

[20] Wang X, Hua L, Han X, Wang X, Wang D, Liu Y (2014) Numerical simulation and experimental study on geometry variations and process control method of vertical hot ring rolling. Int J Adv Manuf Technol 73(1-4): 389-398. https://doi.org/10.1007/s00170-014-5770-2

[21] Chekmarev AP, Klimenko PA, Vinogradov GA (1963) Investigation of specific pressure, specific friction, and the coefficient of friction during metal powder rolling. Sov Powder Metall+ 2(2): 112-115. http://dx.doi.org/10.1007/BF01111823 
[22] Volkogon GM, Dmitriev AM, Dobryakov EP (1991) Advanced technological processes stamping parts from powders and equipment. Mechanical Engineering, p. 320 (in Russian)

[23] Katashinskii VP, Shtern MB (1983) Stress-strain state of powder being rolled in the densification zone. I. Mathematical model of rolling in the densification zone. Powder Metall. Met. Ceram. 22 (11): 882 885. https://doi.org/10.1007/BF00805540

[24] Katashinskii VP, Shtern MB (1983) Stress-strain state of powder being rolled in the densification zone. Powder Metall. Met. Ceram. 22 (12): 972-976. https://doi.org/10.1007/BF00802421

[25] Stepanenko AV, Isaevich LA, Kharlan VE (1990) Geometric and power parameters of the metal powder rolling process. I. Boundaries of the seat of deformation and stress field in the lag and forward slip zones. Powder Metall. Met. Ceram. 29 (2): 101-105. https://doi.org/10.1007/BF00794530

[26] Stepanenko AV, Isaevich LA, Kharlan VE (1991) Geometric and energy-force parameters of the process of rolling of metal powders II. The rolling power, moment, and contact stresses and distribution of density in the area of deformation. Powder Metall. Met. Ceram. 30 (2): 101-105. https://doi.org/10.1007/BF00797280

[27] Wang PT, Karabin ME (1994) Evolution of porosity during thin plate rolling of powder-based porous aluminum. Powder Technology, 78(1): 67-76. https://doi.org/10.1016/0032-5910(93)02768-6

[28] Gogaev KA, Kalutskii GYa, Voropaev VS (2013) Contact stresses in the deformation zone and average pressure during asymmetric rolling of metal powders. Powder Metall Met C+ 52(3-4): 126-131. https://doi.org/10.1007/s11106-013-9504-z

[29] Chigarev VV, Belik, AG, Gribkov EP, Gavrish PA (2015) A mathematical model of the process of rolling flux-cored tapes. Weld Int 26 (9): 718-722. https://doi.org/10.1080/09507116.2014.888192

[30] Chigarev VV, Gavrish PA, Gribkov EP (2012) Investigation of the process of drawing flux -cored wire for welding copper to steel. Weld Int 29 (1): 70-74. https://doi.org/10.1080/09507116.2011.653152

[31] Chigarev VV, Gavrish PA, Gribkov EP (2014) Improving the technological conditions of drawing flux-cored welding wires. Weld Int 28 (1): 59-61. https://doi.org/10.1080/09507116.2013.796655

[32] Potapkin VF, Levkin AN, Satonin AV, Romanov SM, Vorob'yev YuA, Gribkov, EP (2000) Stress state and kinematics for rolling of powered materials on metal substrate. Powder Metall Met C+ 39 (1-2): 1117. https://doi.org/10.1007/BF02677434

[33] Gribkov EP, Perig AV, Danilyuk VA (2015) Research into the process of producing powder tapes. Int J Adv Manuf Technol 77 (95-8): 1087-1104. https://doi.org/10.1007/s00170-014-6496-X

[34] Gribkov EP, Perig AV (2016) Research into the process of producing powder tapes. Int J Adv Manuf Technol 85: 2887-2900. https://doi.org/10.1007/s00170-016-8714-1

[35] Gribkov EP, Berezshnaya EV, Hurkovskaya SS, Malyhina SV (2018). Study into the rolling of a double-layered powdered core in a metallic sheath. Eastern-European Journal of Enterprise Technologies. 6: 71-79. https://doi.org/10.15587/1729-4061.2018.150081

[36] Hrudkina N, Aliieva L, Markov O, Marchenko I, Shapoval A, Abhari P, Kordenko M (2020) Predicting the shape formation of hollow parts with a flange in the process of combined radial-reverse extrusion. EasternEuropean Journal of Enterprise Technologies 4(106): 55-62. https://doi.org/10.15587/1729-4061.2020.203988

[37] Menezes, P.L., Kumar, K., Kishore et al. (2009) Influence of friction during forming processes - a study using a numerical simulation technique. Int J Adv Manuf Technol 40, 1067-1076. https://doi.org/10.1007/s00170$\underline{008-1425-5}$

[38] Mori K., Osakada K. (1987) Analysis of the forming process of sintered powder metals by rigid-plastic finiteelement method. Int. J. Mech. Sci. 29(4): 229-238. https://doi.org/10.1016/0020-7403(87)90037-3

[39] Zheng ZX, Xia W, Zhou ZY (2013) Experimental and numerical modeling for powder rolling. Rev. Adv. Mater. Sci. 33: 330-336. https://doi.org/10.4028/www.scientific.net/AMM.159.115

[40] Lambiase F, Di Ilio A (2012) Deformation inhomogeneity in roll drawing process. Journal of Manufacturing Processes 14: 208-215. https://doi.org/10.1016/j.jmapro.2011.12.005

[41] Lambiase F, Di Ilio A (2012) Experimental and Finite Element Investigation of Roll Drawing Process. J Mater Eng Perform 21(2):161-166. https://doi.org/10.1007/s11665-011-9932-1

[42] Amine K El, Larsson J, Pejryd L (2018) Experimental comparison of roller die and conventional wire drawing. Journal of Materials Processing Technology 257: 7-14. https://doi.org/10.1016/j.jmatprotec.2018.02.012

[43] Kim JH, Ko DC, Kim BM (2019) New tandem drawing process through non-driven four roll-die and converging die. Journal of Materials Processing Tech. 263: $470-478$. https://doi.org/10.1016/j.jmatprotec.2018.08.016

[44] Hwang JK (2020) Deformation Behaviors of Flat Rolled Wire in Twinning-Induced Plasticity Steel. Met. Mater. Int. 26: 603-616. https://doi.org/10.1007/s12540-019-00363-7

[45] Polyakova M, Gulin A, Golubchik E (2018) Assessment of Structure Integrity and Mechanical Properties of Carbon Steel Wire in Combined Deformation Processing. Key Engineering Materials $769: 277$ 283. https://doi.org/10.4028/www.scientific.net/KEM.769.277

[46] Poluhin PI et al (1982) Rolling production. Metallurgy, Moscow (in Russian). 
Figures

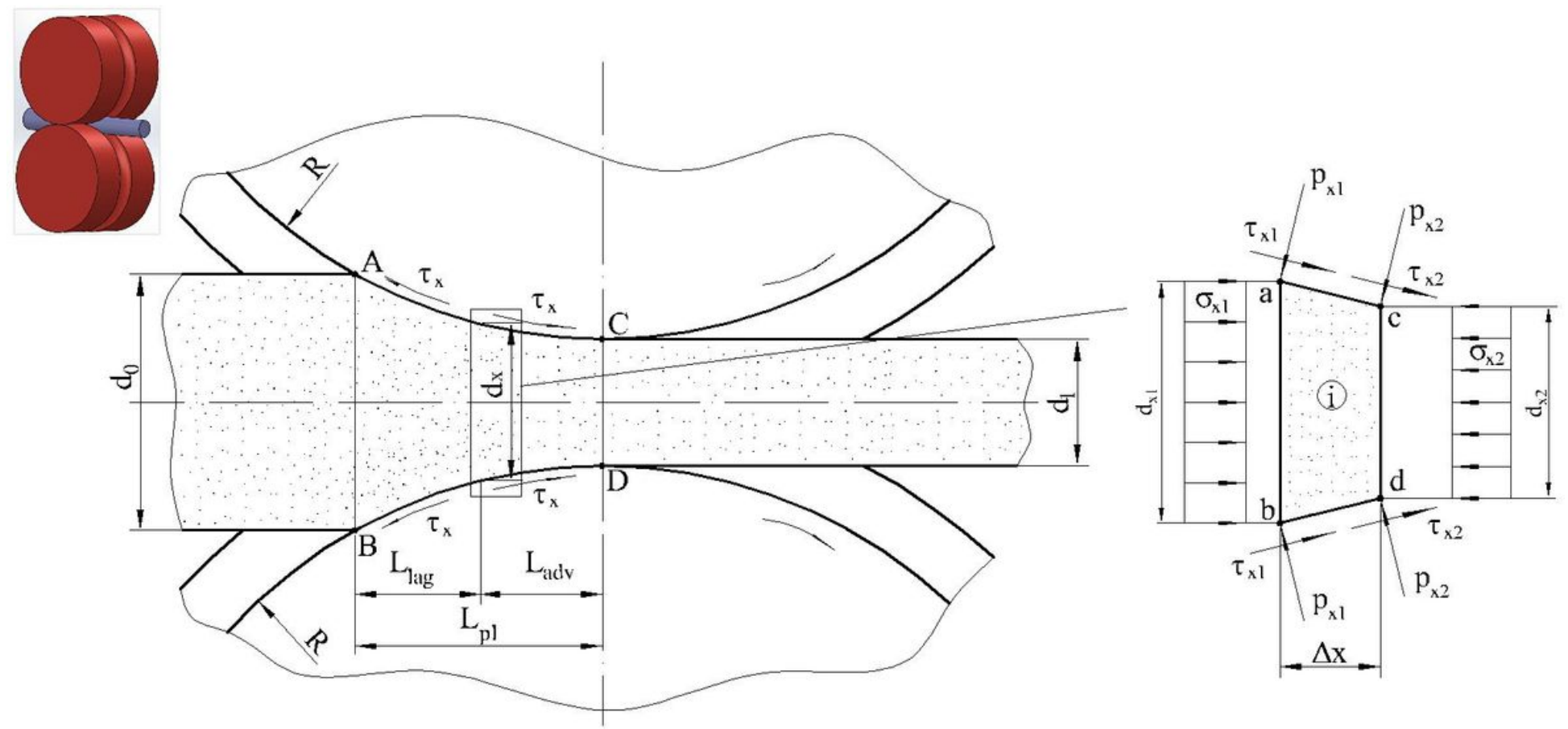

Figure 1

Design diagram of the integral deformation zone (a) and the selected elementary volume (b) during the implementation of the pressed flux-cored wire rolling process 

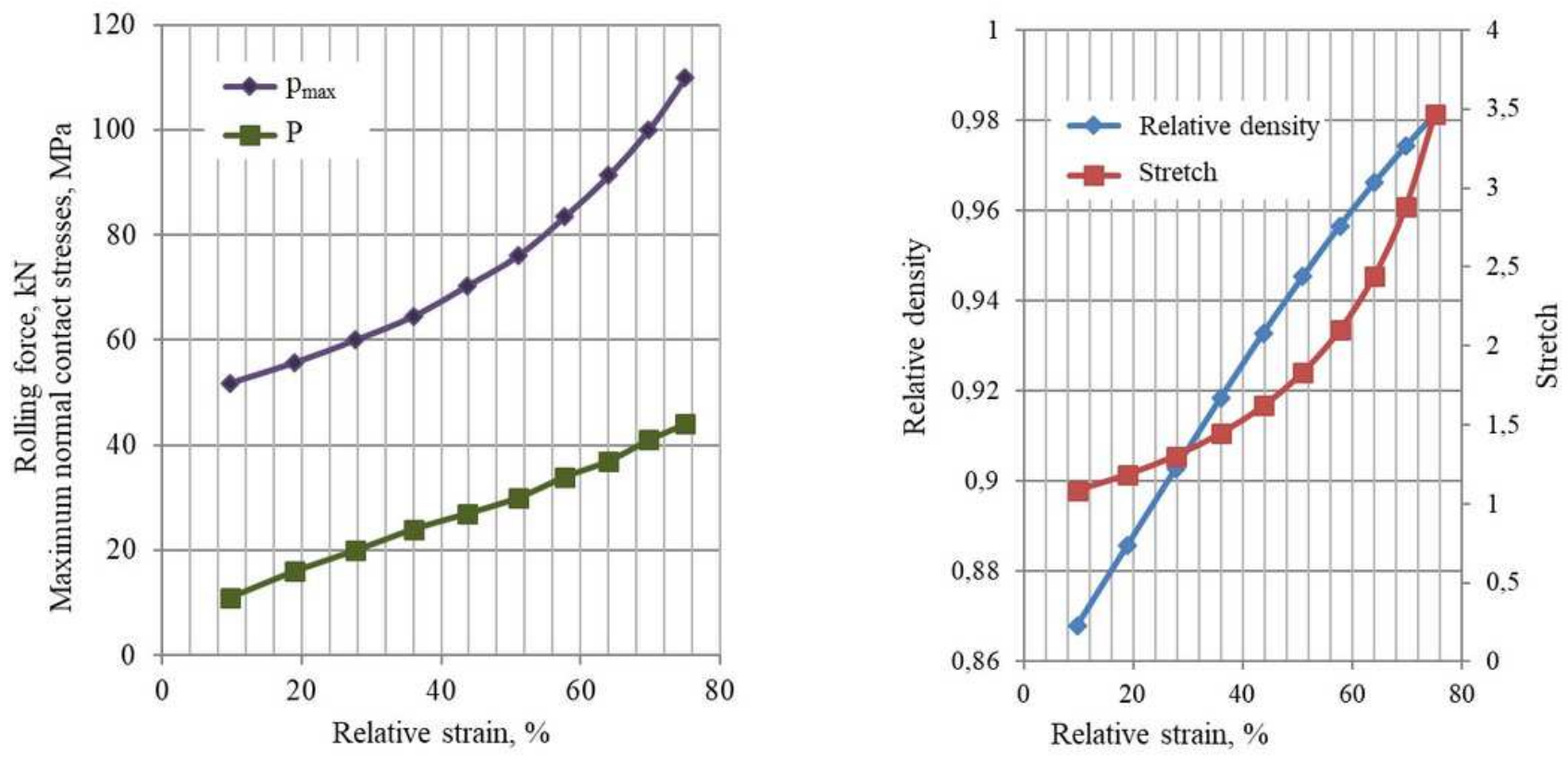

Figure 2

Calculated distributions of the flux-cored wire rolling integral characteristics depending on the degree of reduction: rolling force (a) and relative density (b)
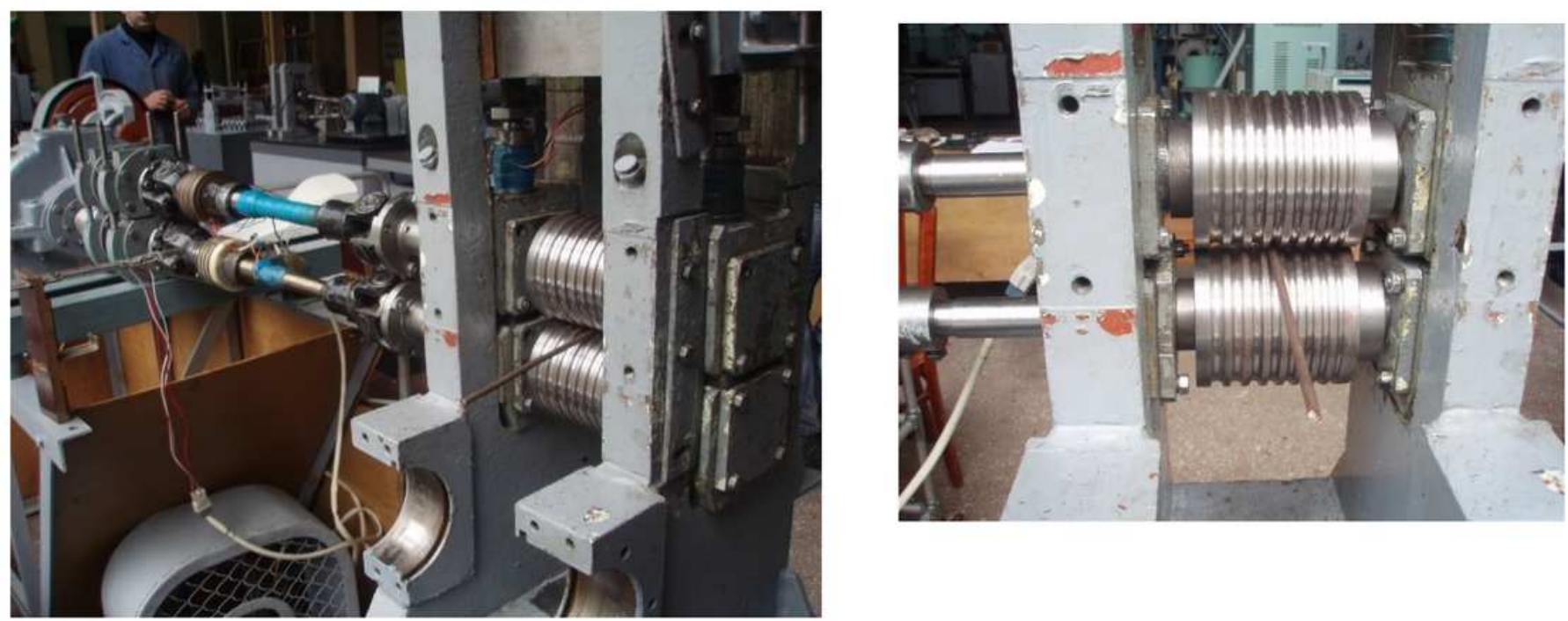

\section{Figure 3}

General view of roll mill stand 100 with rolls for rolling flux-cored wire rolling 


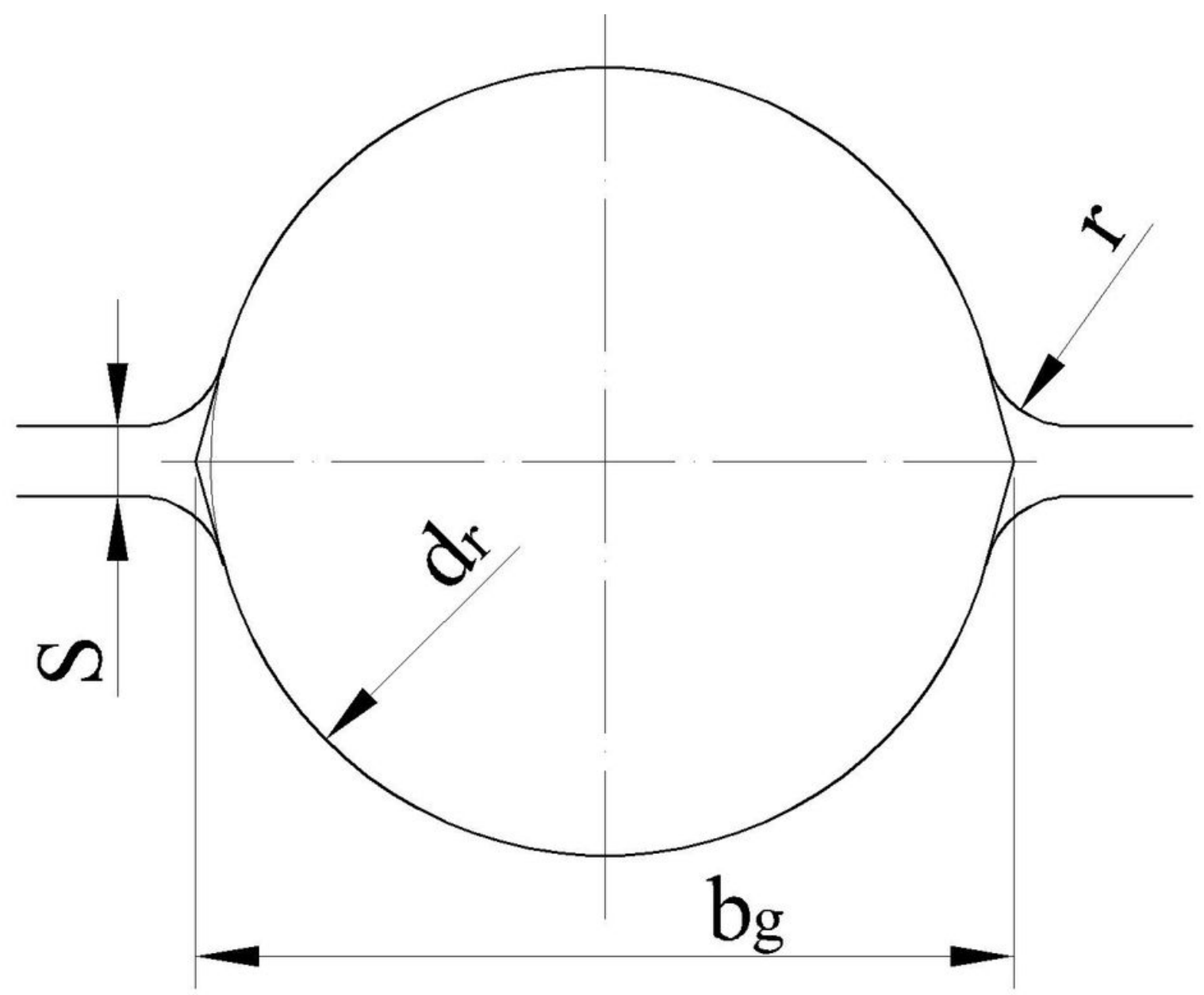

Figure 4

Construction of a finishing gauge for rolling pressed flux-cored wire

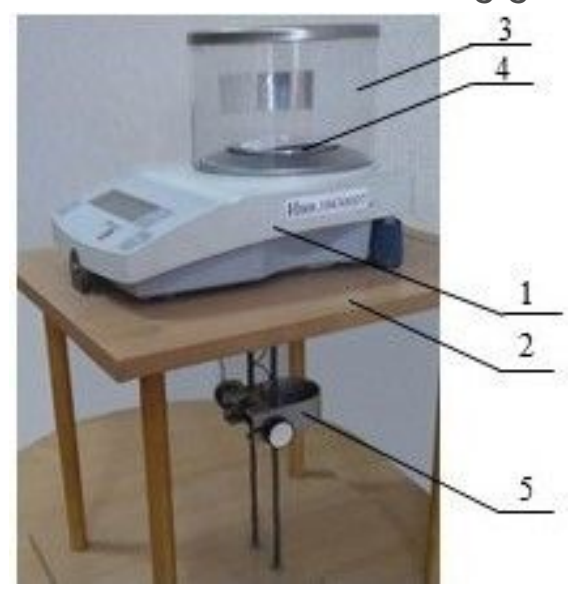

Figure 5

Unit for hydrostatic weighing the samples ( 1 - electronic analytical balance, 2 - stand, 3 - measuring cylinder, 4 - sample, 5 - supporting block) 

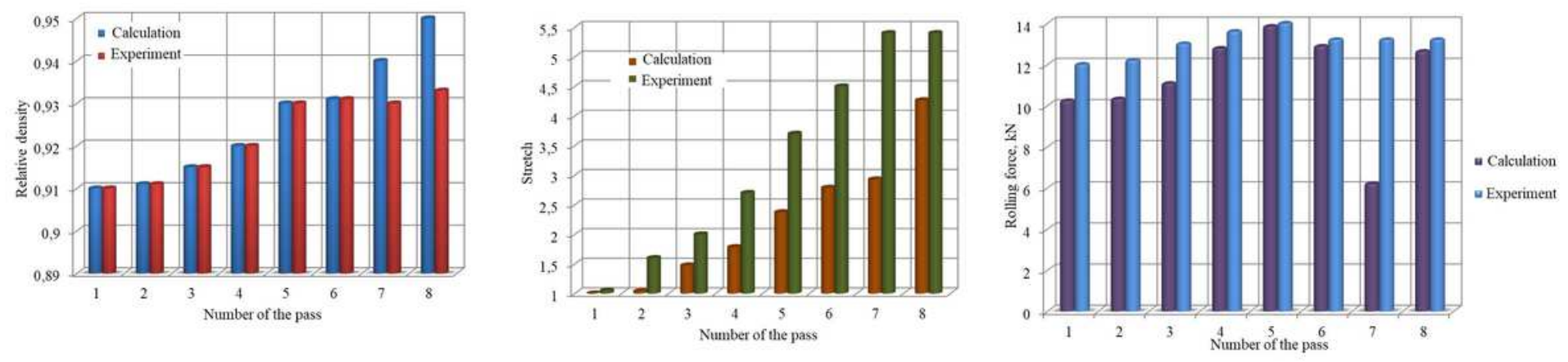

Figure 6

Theoretical and experimental distributions of the integral characteristics for the flux-cored wire rolling through passes: relative density (a), drawing (b), rolling force (c) 


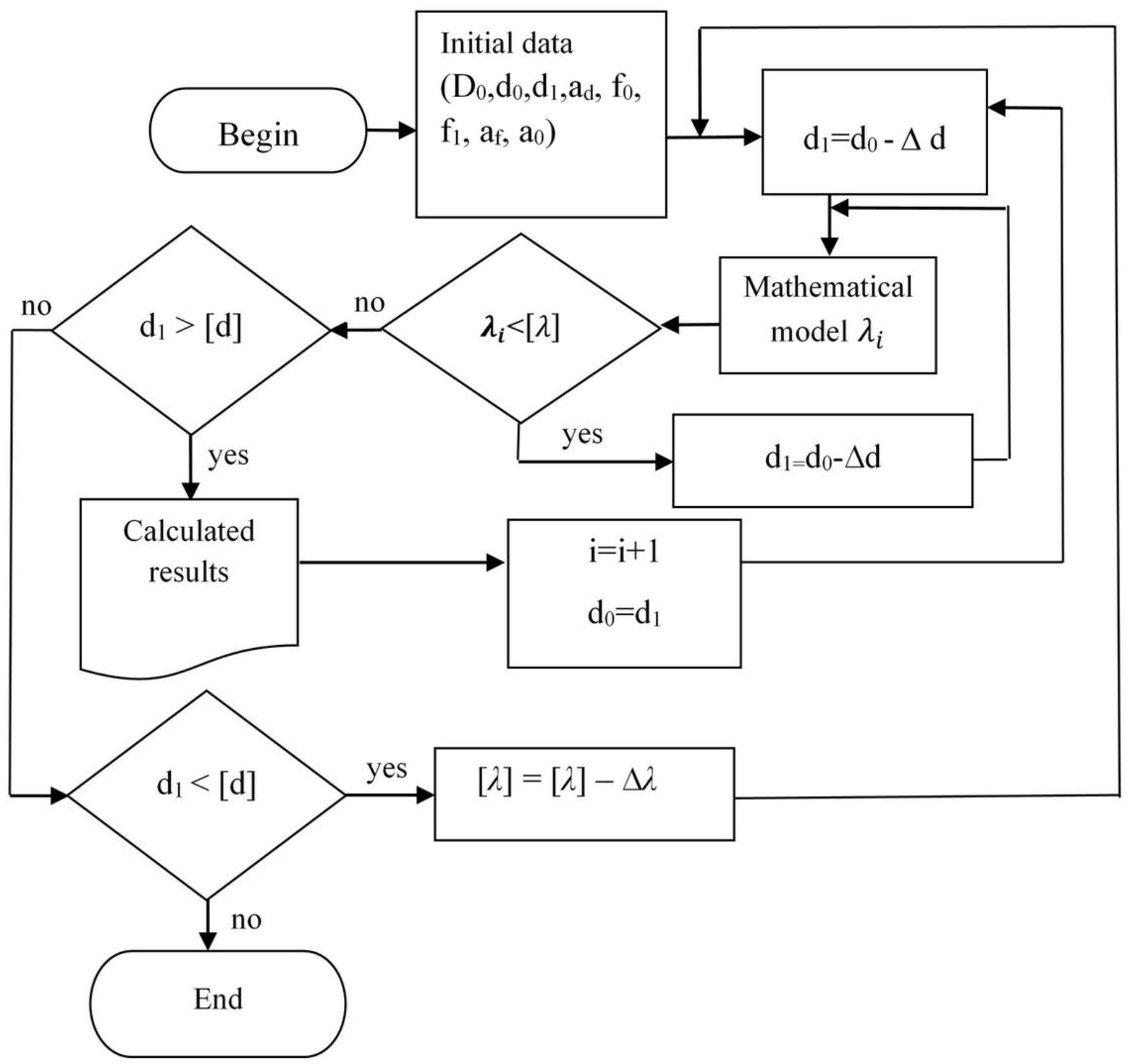

Figure 7

The enlarged block diagram of the algorithm for solving the automation process when rolling pressed flux-cored wire 